\title{
Study on the Seismic Performance of Different Combinations of Rubber Bearings for Continuous Beam Bridges
}

\author{
Yumin Zhang $\mathbb{D}^{1,2}$ Jiawu Li $\mathbb{D}^{1},{ }^{2}$ Lingbo Wang $\mathbb{D}^{2},{ }^{2}$ and Hao Wu $\mathbb{D}^{2}$ \\ ${ }^{1}$ Department of Civil Engineering, Xi'an Shiyou University, Xi'an 710065, China \\ ${ }^{2}$ Shaanxi Key Laboratory of Highway, Bridge and Tunnel, Highway College of Chang'an University, Xi'an 710064, China
}

Correspondence should be addressed to Yumin Zhang; zhangyumincorn@163.com

Received 11 May 2020; Revised 23 September 2020; Accepted 24 September 2020; Published 19 October 2020

Academic Editor: Tiago Ferreira

Copyright (C) 2020 Yumin Zhang et al. This is an open access article distributed under the Creative Commons Attribution License, which permits unrestricted use, distribution, and reproduction in any medium, provided the original work is properly cited.

Rubber isolation bearings have been proven to be effective in reducing the seismic damage of bridges. Due to the different characteristics of isolation bearings, the mechanical properties of bridges with different combinations of rubber bearings are complex under the action of earthquakes. This paper focuses on the application of combinations of rubber isolation bearings on seismic performance of continuous beam bridges with T-beams. The seismic performances of continuous beam bridges with different combinations of rubber isolation bearings, pier height, and span length were studied by the dynamic time history analysis method. It was found that the bridges with natural rubber bearings (NRBs) have the largest seismic responses compared to the other types of bearings. The continuous beam bridge with isolation bearings, such as lead rubber bearings (LRBs) and high damping rubber bearings (HDRBs), has approximately 20\% 30\% smaller seismic response than that with NRBs under the action of earthquakes due to the hysteretic energy of the bearings, indicating that the isolation bearings improve the seismic performance of the bridge. The continuous beam bridges with both NRBs and LRBs or NRBs and HDRBs have larger seismic response of the piers than those with a single type of isolation bearings (LRBs or HDRBs) but smaller seismic response of the piers than those with only NRBs. For a continuous beam bridge with shorter span and lower pier, it is not economical to use LRBs or HDRBs underneath every single girder, but it is more reasonable to use cheaper NRBs underneath some girders. The larger difference in stiffness of the bearings between the side and middle piers leads to the more unbalanced seismic response of each pier of the bridge structure. The results also show that with increasing pier height and span length, the difference in the seismic response value between the cases gradually increases.

\section{Introduction}

Among the seismic performance of a continuous beam bridge, traffic safety is of great concern $[1,2]$. In recent years, rubber materials have been widely used for the bearings of bridges because of their excellent deformation characteristics. They play an important role in the seismic design of continuous beam bridges [3-6]. Research on the material and mechanical properties of different rubber bearings is helpful to understand the seismic performance of rubber bearings in bridge structures, thereby guaranteeing no serious damage to the continuous beam bridge under the action of earthquakes $[7,8]$.

Numerous studies have proved the efficiency of rubber bearings in reducing the seismic-induced forces of bridge systems [9, 10]. The common types of rubber isolation bearings include low damping natural rubber bearings (LDRs) [1], natural rubber bearings (NRBs) [3, 6], lead rubber bearings (LRBs) [7], and high damping rubber bearings (HDRBs) [2, 8]. At present, the seismic performance of the aseismic bearings for continuous beam bridges is mainly studied for the mechanical behavior of various rubber bearings under earthquakes $[11,12]$, by utilizing the finite element method and shaking table test methods [13-16]. Yamamoto et al. [17] investigated the seismic characteristics of the isolation bearings of bridge structure and found that for a structure under instantaneous load, the isolation bearings can effectively reduce the seismic input and can affect the characteristics of the structure in the frequency domain. Pradilla and Cho [18] presented a 
comparison of the seismic behavior of simply supported bridges by using three types of isolators, including HDRBs, LRBs, and a friction pendulum system. Losanno et al. [19] analyzed the seismic performance of a three-span continuous bridge designed with different isolation systems, including simply supported, LRBs, isolated with rubber isolators and $10 \%$ damping, and isolated with rubber isolators and a 70\% supplemental damping ratio. Six near-fault ground motion records were used to analyze the seismic performance of a bridge by the direct time history integration method. Tubaldi et al. [8] revealed that in simply supported multispan bridges, the HDRBs typically placed in two lines of support and eccentric with the pier axis induces a coupled horizontal vertical response of the bearings. Wang et al. [20] investigated the seismic response of a typical continuous beam bridge isolated with friction sliding bearings in the Hong Kong-Zhuhai-Macao Link Project of China. Li et al. [2] performed the shaking table array test of a two-span isolated continuous bridge specimen with the scale of $1: 3$ to study the seismic response characteristics of the continuous bridge with HDR bearings. Zheng et al. [21] investigated the seismic performance of the bridges with a sliding-lead rubber bearing (LRB) isolation system under the action of near-fault earthquakes. For the bridges with tall piers, Chen and Li [11] investigated the effect of different seismic retrofitting measures including LRBs and rocking foundations on mitigation of their seismic responses. Anajafi et al. [22] investigated the effect of LRBs on improvement of the seismic performance of the bridges with flexible piers in near-field and far-field earthquakes. Their studies show that for far-field ground motions, the LRBs used significantly reduce not only the substructure responses but also the displacement response of the girder. For near-fault excitations, their studies show that there is an optimum range of bearing parameters that can reduce the substructure force demand and keep the girder displacement demand in practice. Zhen et al. [23] used a high-speed multispan continuous beam bridge with equal section as the engineering background to discuss the seismic isolation effect of LRBs and fluid viscous dampers by the dynamic time history analysis method. Current research mainly focuses on the mechanical behaviors of a single type of bearings. The combination of different bearings is seldom studied. To save the construction cost, many kinds of bearings are used for the bridges in practice.

Additionally, the continuous beam bridge with a combination of different bearings has more complicated response to earthquakes because (1) LRBs and HDRBs have nonlinear horizontal stiffness, quite different from NRBs especially at high shear strain amplitudes, and (2) some factors, such as pier height and span length, also influence the seismic performance of the bridges [24-26]. Researchers have investigated the failure modes and seismic performance of a continuous beam bridge with a combination of different bearings during strong ground motions [21, 27]. However, the influencing factors are studied very rarely based on a combination of different bearings. What is more, the importance of the combinations of different bearings has not been clarified.
In this paper, the seismic performance of continuous beam bridges with combinations of different rubber bearings, such as a combination of NRBs, LRBs, HDRBs, NRBs, and LRBs, and a combination of NRBs and HDRBs, were studied; the bridges with such combinations were compared to the bridges without bearings; the influence of bearing combination, pier height, and span length on the seismic response, including the displacement and energy dissipation of bearings, the displacement of the girder, the displacement of the top of the piers, and the bending moment and shearing force of the bottom of the piers, were discussed. The isolation design method for the continuous beam bridges with T-beams was provided; the effects of different combinations of rubber bearings on the mechanical performance of the bridges were studied in order to further understand the optimal configuration of different pier heights and span lengths and provide rational suggestions for selection of bearings for the continuous bridges with T-beams.

\section{Materials and Mechanical Properties of Rubber Bearings}

2.1. Material Properties of Rubber Bearings. Rubber is a highly elastic synthetic polymer material, including natural and synthetic rubber [28]. The mechanical properties of rubber materials are relatively complex; the stress-strain relationship of rubber materials is approximately linear in the case of small strain but nonlinear in the case of large strain [29]. Among synthetic rubbers, high damping rubber is an effective isolation material typically filled with carbon black, oils, or resins, which can enhance the seismic performance of structures due to its higher damping properties, energy dissipation capability, and flexible stiffness $[30,31]$.

Rubber material has been widely used in the bearings of bridge structures, and isolation rubber bearings are especially suitable for the design of the seismic isolation for bridges because of their seismic properties [8]. HDRBs consist of high damping rubber layers, providing bearings with horizontal flexibility, reinforced with steel layers that provide vertical stiffness [32], as shown in Figure 1(a). The shape and high damping characteristics of LRBs are similar to that of HDRBs; the difference is that LRBs have lead cores vertically inserted into the bearings, as shown in Figure 1(b). The lead cores can change the damping characteristics of the bearings so that they can adopt antiseismic and energy absorption properties during earthquakes [33].

Both LRBs and HDRBs have high horizontal stiffness and damping at low shear strains, which can reduce the response of bridges within a reasonable range under service loads and small earthquakes. Furthermore, their horizontal stiffness changes after the bearings yield with large horizontal shear force and displacement during larger earthquakes, and so the bearings can absorb seismic energy $[23,30]$. A high damping ratio is also an important characteristic of LRBs and HDRBs in addition to the nonlinear constitution relation of conventional rubber materials. 


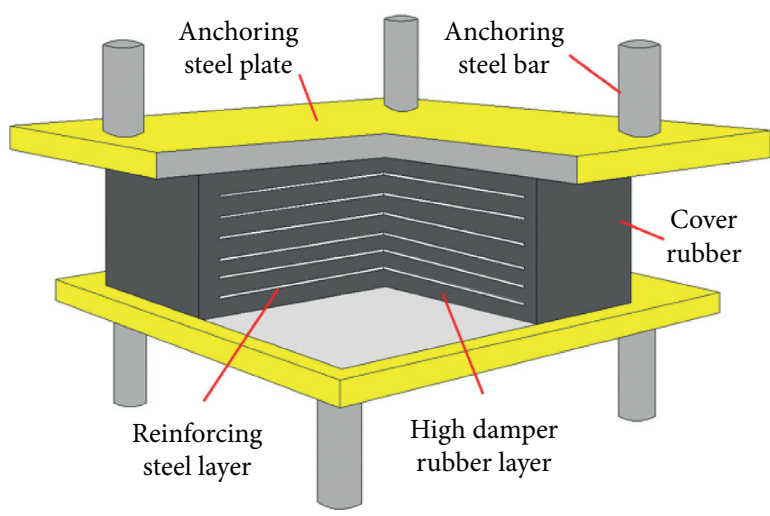

(a)

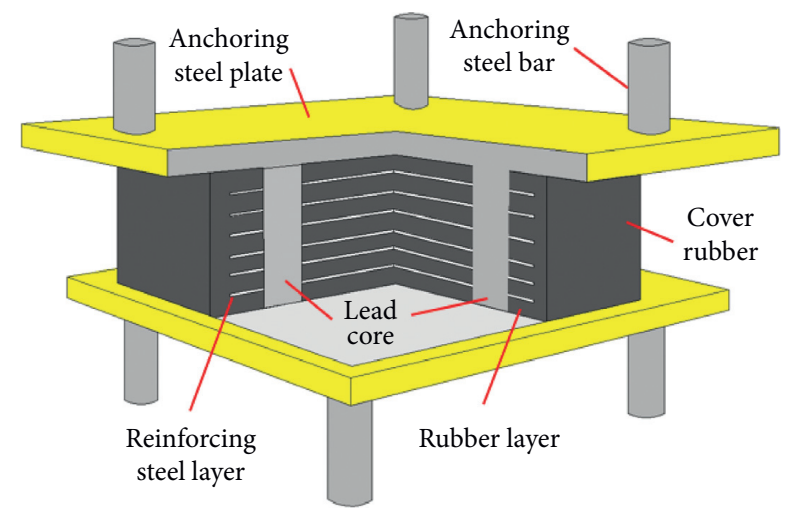

(b)

FIGURE 1: Structural composition of isolation bearings: (a) HDRB; (b) LRB.

\subsection{Mechanical Properties of Rubber Bearings. Rubber} bearings not only need to support the superstructure of a bridge but also satisfy the deformation demand of the bridge under the action of external forces. Especially under the action of large earthquakes, bridge structures have a larger displacement and the bearings have a larger shear deformation [34]. LRBs and HDRBs can extend the overall period of the bridge structure by yielding, effectively avoiding the outstanding period of the earthquake, and reducing the seismic response of the superstructure based on the high damping characteristics, so as to achieve the effect of isolation [27]. The shear performance curve of LRBs and HDRBs under horizontal load is shown in Figure 2.

The equivalent horizontal stiffness, $K_{h}$, of LRBs and HDRBs is calculated according to the equation below:

$$
K_{h}=G_{\text {eq }}(\gamma) \frac{A}{T_{r}}
$$

where $G_{\mathrm{eq}}$ is the equivalent shear modulus at the shear strain of $\gamma$; $A$ is the plane area of the rubber inside the bearing, i.e., the effective area; and $T_{r}$ is the total thickness of the rubber of the bearing.

The initial horizontal stiffness is calculated according to the following equation:

$$
K_{i}=\frac{2 \cdot U(\gamma)-\pi \cdot h_{\mathrm{eq}}(\gamma)[1-U(\gamma)]}{2 \cdot U(\gamma)-\pi \cdot h_{\mathrm{eq}}(\gamma)} \cdot K_{h},
$$

where $U(\gamma)$ is the ratio of yield force to shear force at the shear strain of $\gamma$ and $h_{\mathrm{eq}}(\gamma)$ is the equivalent damping ratio. $U(\gamma)$ and $h_{\text {eq }}(\gamma)$ are calculated according to equations (3) and (4), respectively:

$$
\begin{gathered}
U(\gamma)=\frac{Q_{d}}{K_{h}\left(T_{r} \gamma\right)}, \\
h_{e q}(\gamma)=\frac{W_{d}}{2 \pi K_{h}\left(T_{r} \gamma\right)^{2}},
\end{gathered}
$$

where the yield force, $Q_{d}$, is experimentally determined, and $W_{d}$ is the energy consumed for each loading cycle, i.e., the envelope area of the hysteresis curve of LRBs and HDRBs.
The postyield stiffness, $K_{d}$, is calculated according to the following equation:

$$
K_{d}=[1-U(\gamma)] K_{h} .
$$

From the viewpoint of dynamics, the dynamic equation of bridge structures under the action of the earthquakes can be expressed as follows [35]:

$$
m \ddot{x}(t)+c \dot{x}(t)+k x(t)=-m \ddot{x}_{0}(t),
$$

where $\ddot{x}(t), \dot{x}(t)$, and $x(t)$ are the acceleration, velocity, and displacement response of the bridge structure, respectively; $\ddot{x}_{0}(t)$ is the acceleration time history of the ground motion on the bridge structure, $m$ is the mass of the structure, $c$ is the damping, and $k$ is the rigidity.

It can be seen from the dynamic equation that for a bridge structure with isolation bearings, its seismic response under the action of an earthquake can be changed by changing $m, c$, and $k$. For example, by changing the damping, $c$, and the rigidity, $k$, of the bridge structures, LRBs and HDRBs can reduce the seismic response and thereby avoid seismic damage to the bridge structures.

\section{Model of a Bridge}

3.1. Physical Model of a Bridge. Figure 3 shows the simplified geometry and a detailed structural drawing of the continuous beam bridge studied in this paper. Figure 3(a) shows a $3 \times 50 \mathrm{~m}$ physical model of a continuous beam bridge, for which the piers are $50 \mathrm{~m}$ tall. The compressive strength of the concrete used for the girder and piers are $50 \mathrm{MPa}$ and $40 \mathrm{MPa}$, respectively. Figure 3 (b) shows that the girder of the bridge is composed of six T-beams; the bridge has a total width of $12.25 \mathrm{~m}$, and the T-beams are $2.8 \mathrm{~m}$ tall; the deck pavement is composed of $8 \mathrm{~cm}$ thick $\mathrm{C} 40$ cement concrete and $10 \mathrm{~cm}$ thick asphalt concrete. Figure 3(c) shows the transverse, longitudinal and cross-sectional views of the pier from left to right. The piers are thin-walled and hollow with a sectional area of $6 \times 4 \mathrm{~m}$, a minimum section wall thickness of $0.5 \mathrm{~m}$, and a maximum section wall thickness of $1 \mathrm{~m}$. The yield strength of the steel used for piers is $400 \mathrm{MPa}$ (according to Chinese code GB50010-2010) [23]. The pier 


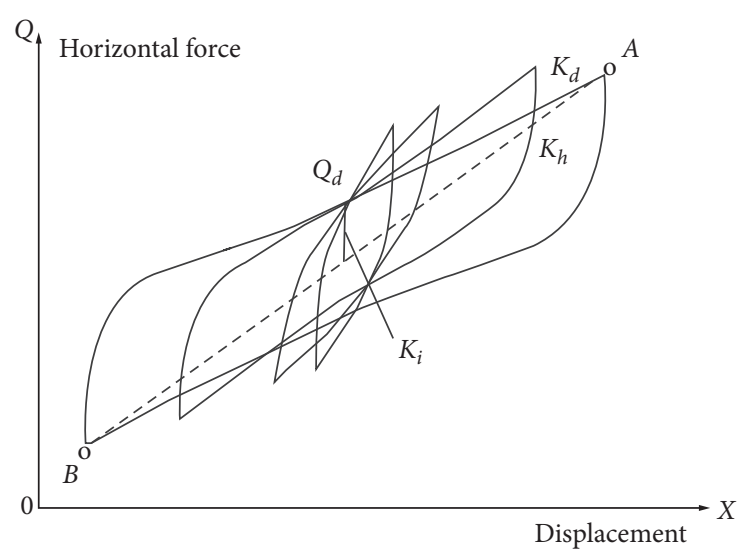

FIGURE 2: Shear performance curve of LRBs and HDRBs.

cap beams are $11.8 \mathrm{~m}$ long, $4.2 \mathrm{~m}$ wide, and $2.4 \mathrm{~m}$ tall; the caps are $8.3 \times 8.3 \mathrm{~m}$ quadrates and $3 \mathrm{~m}$ tall.

3.2. Finite Element Model. A 3-D model of the bridge structure was created by the nonlinear finite element program MIDAS [36, 37]. The simplified analysis model of the bridge is shown in Figure 4(a). The superstructure and substructure of the bridge were simulated by the lumped mass system and the small discrete segment method. The appropriateness of such a modeling approach for a bridge has been proven by the research of Choi et al. [38]. Zhang and Huo [39] verified the accuracy of the program by comparing the test results of static and dynamic loading experiments. In the bridge structure modeling, the girder was simulated by using elastic beam elements, while the bearings and piers were simulated by nonlinear elements. In the modeling details of the bridge system, piers, and bearings, as shown in Figure 4(b), elastic linear beam-column elements were used for girder; bilinear link elements were used for the bearings; rigid elements were used to connect the girder and piers with bearings; and fibre-based nonlinear elements were used to model the piers [40, 41]. The details of fibre-based nonlinear elements and the stress-strain relationship of unconfined concrete, confined concrete, and longitudinal steel reinforcement used for the pier sections are shown in Figure 4(c). The compressive strength of the unconfined concrete, confined concrete, and the yield stress of the steel reinforcement are $26.8 \mathrm{MPa}, 29.2 \mathrm{MPa}$, and $345 \mathrm{MPa}$, respectively $[23,37]$. The base of the pier, fixed as the interaction effect of the soil and the structure, was neglected [42]. The model had a total of 572 nodes, 48 nonlinear beam-columns, 600 elastic linear beam-columns, and 24 bilinear link elements.

3.3. Model for Rubber Bearings. In this paper, the aseismic performance of different combinations of rubber bearings for the bridges was studied. According to the recommendations for the parameters of $50 \mathrm{~m}$ T-beam bearings in the Chinese standard, three different types of bearings, NRBs, LRBs and HDRBs, were selected for the bridge structure, respectively [6-8].
All of the bearings were simulated by bilinear elastic plastic spring element. The restoring force model of the sliding and fixed NRBs is shown in Figure $5(\mathrm{a}) . K_{0}$ is the bearing stiffness, $x_{0 y}$ is the yield displacement, and $Q_{0 y}$ is the sliding frictional force [43]. The stiffness of LRBs and HDRBs is nonlinear, which was simulated by a mechanical model of bilinear restoring force as shown in Figure 5(b). $K_{1}$ is the preyield stiffness, $K_{2}$ is the postyield stiffness, $K_{h}$ is the equivalent horizontal stiffness, $x_{y}$ is the yield displacement, $x_{d}$ is the limiting displacement, $Q_{y}$ is the yield force, and $Q_{d}$ is the limiting shear force of bearings $[36,44]$.

\section{Case Setting}

4.1. Case Setting of Bearings. As the reaction forces of each pier are different, different combinations of bearings for the bridge were selected according to their vertical bearing force [45]. Based on the static analysis, the support reacting force of the bearings of the four piers was nearly symmetric [46-48]. The characteristics, such as bearings constructability, availability, and technique, are also very important to build a bridge, but the safety of the bridge, especially seismic performance, was studied in this paper [49]. Therefore, the No. 1 pier and No. 4 pier adopted the same type of bearing, while the No. 2 and No. 3 piers had the same type of bearings $[37,50,51]$. The study cases were as follows:

Case 1: without bearings

Case 2: NRBs used for the four piers (NRBs)

Case 3: LRBs used for the four piers (LRBs)

Case 4: NRBs used for the No. 1 and No. 4 piers and LRBs used for the No. 2 and No. 3 piers (NRBs + LRBs)

Case 5: HDRBs used for four the piers (HDRBs)

Case 6: NRBs used for the No. 1 and No. 4 piers and HDRBs used for the No. 2 and No. 3 piers (NRBs + HDRBs)

The case setting of the bearings are shown in Table 1 .

The bearings were mainly selected according to the static analysis results, and the material properties and physical parameters of each bearing are shown in Table 2 (according to the Chinese codes JTT 4-2019, JTT 822-2011, and JTT 842-2012) [24, 44, 52]. The LRBs and HDRBs have nonlinear 


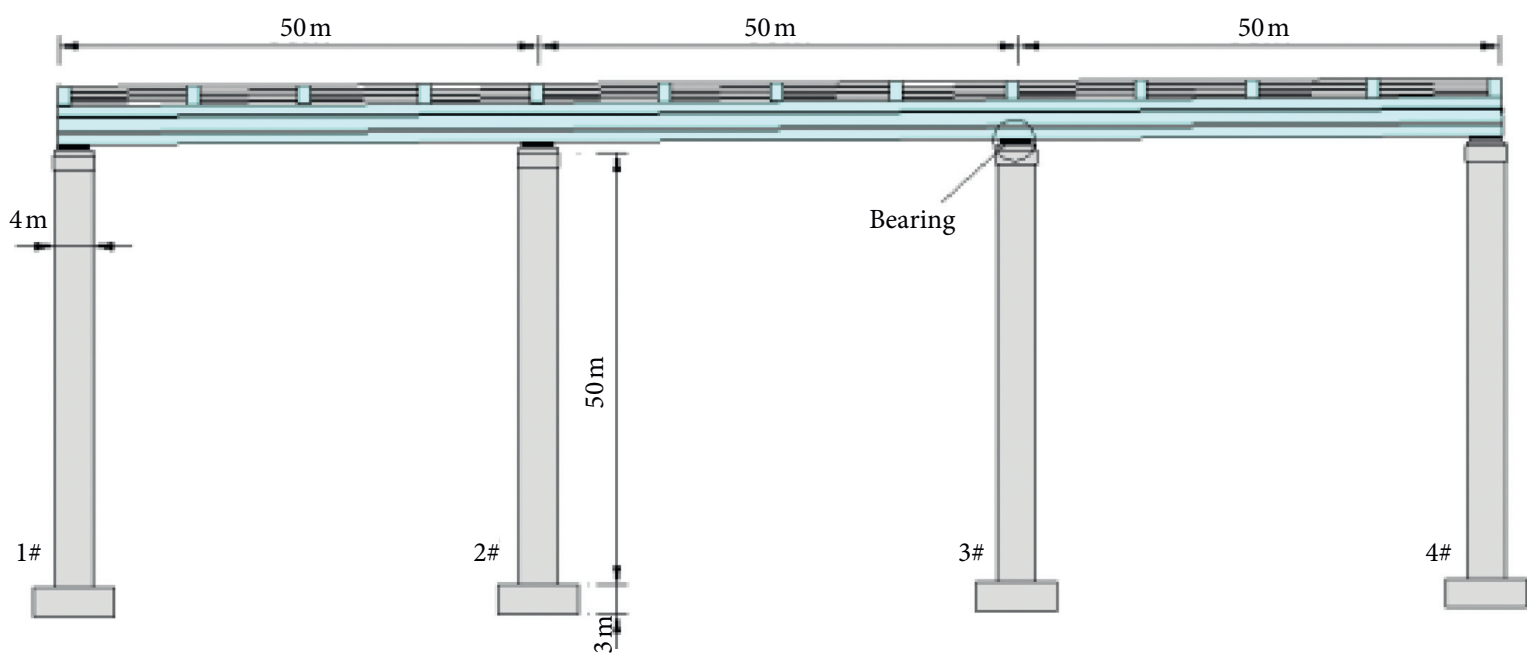

(a)

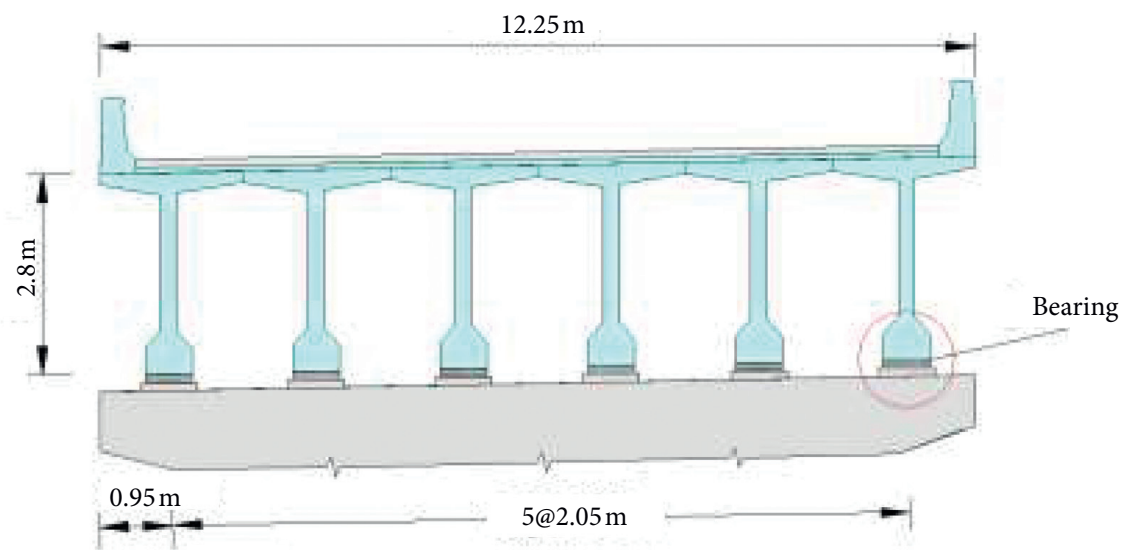

(b)
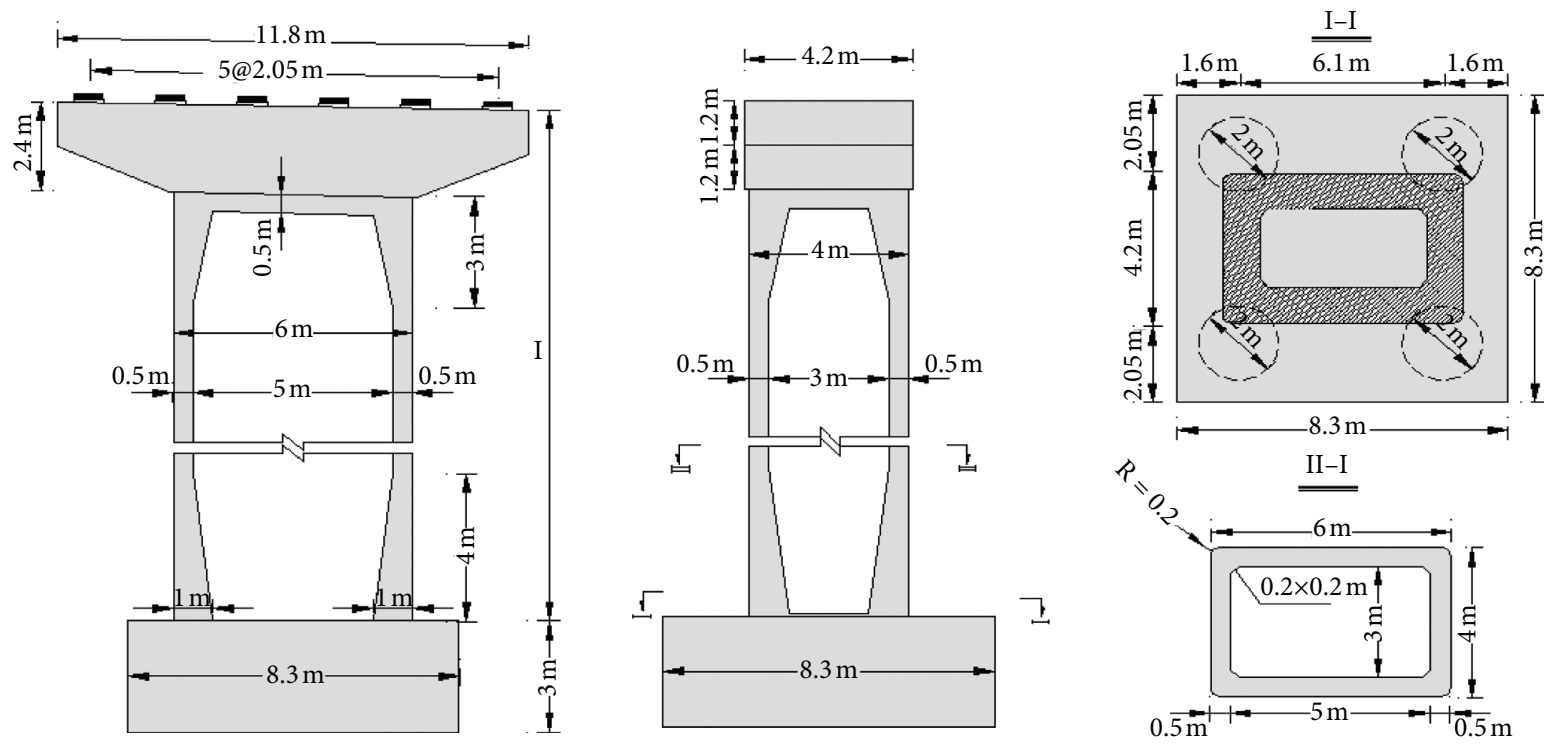

(c)

FIGURE 3: Simplified bridge geometry: (a) longitudinal view of the bridge; (b) transverse view of the superstructure; (c) details of the piers.

horizontal stiffness; as the bearing is subjected to a horizontal seismic force that exceeds its yield force, the preyield stiffness of the bearing becomes postyield stiffness [7, 8].
Considering that the horizontal stiffness of bearings is an important parameter during selection of the design parameters of the bearings, one horizontal equivalent stiffness 


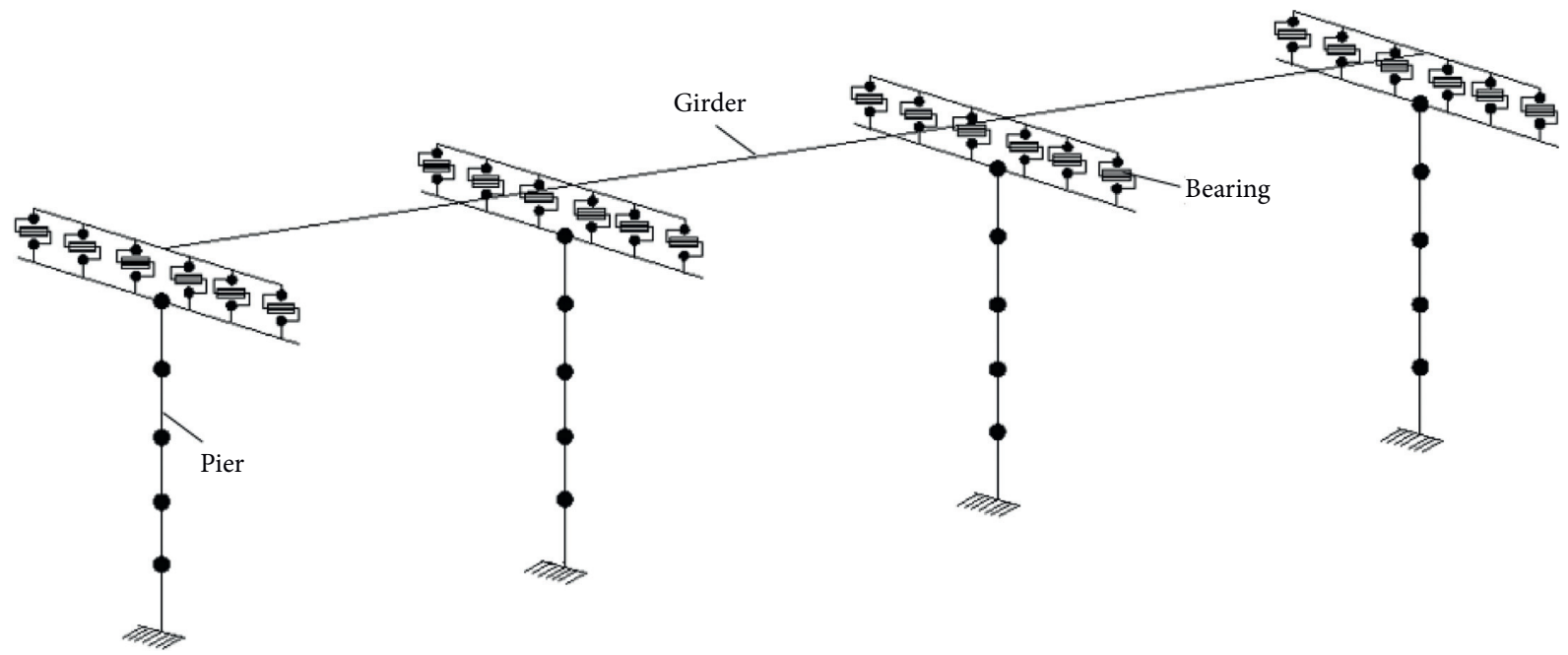

(a)

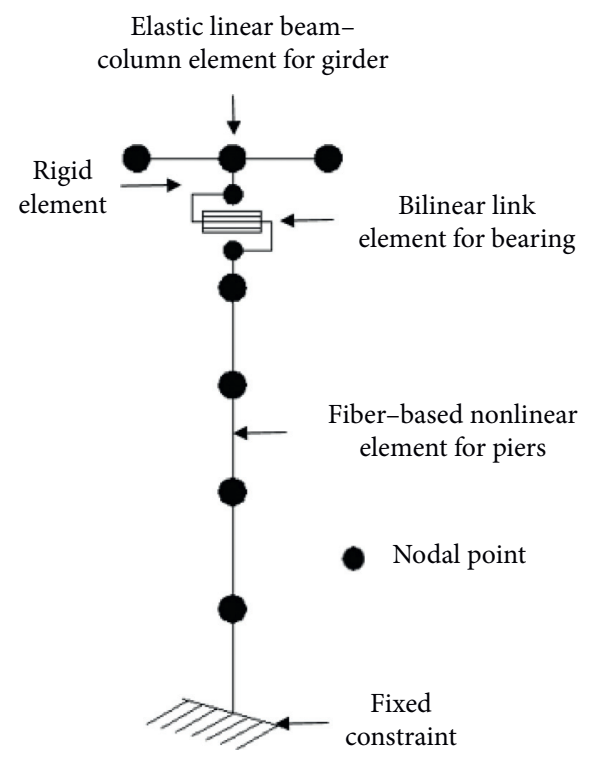

(b)
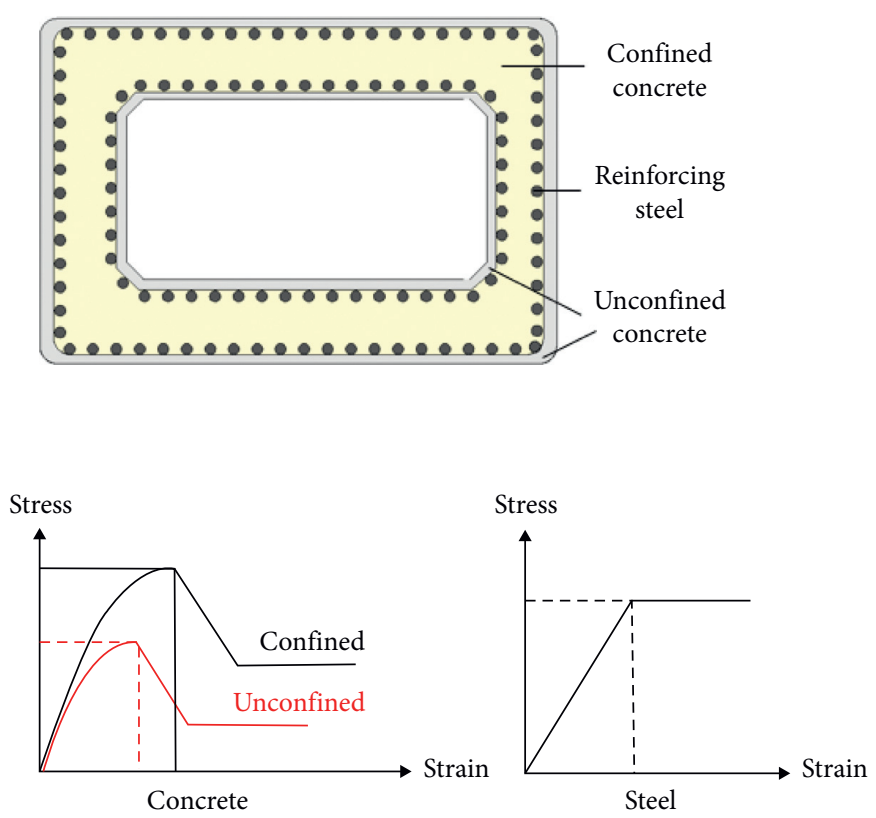

(c)

Figure 4: Analytical model: (a) 3-D finite element model of the total bridge system (girder and deck elements are not shown for clarity); (b) modeling details of an external bridge pier including the nonlinear model used for bearings; (c) details of the fibre-based nonlinear elements used for the pier sections.

value is taken for the bearings on side piers and middle piers through conversion, while the other stiffness parameters of the bearings are converted by the equivalent ratio to facilitate the analysis and comparison.

4.2. Earthquakes. The continuous beam bridge in this study is located in Yan'an city, Shaanxi province in China. The seismic fortification intensity of the site area is 7 , while the site classification of the bridge is III, and the remarkable cycle of the site for small and large earthquakes is $0.56 \mathrm{~s}$ and $0.78 \mathrm{~s}$, respectively $[53,54]$. In order to analyze all of the responses of the bridge structure under different magnitudes of earthquake, time history dynamic analysis was carried out using earthquakes with a probability of $40 \%$ and $2 \%$ in 100 years at the bridge site (three seismic waves in small and large earthquakes, respectively). In addition, there is an autocorrelation between three seismic waves of both small earthquake and large earthquake. Figure 6(a) shows the three seismic time history waves (401, 402, and 403) of small earthquakes, with a peak acceleration value of $0.431 \mathrm{~m} / \mathrm{s}^{2}, 0.436 \mathrm{~m} / \mathrm{s}^{2}$, and $0.43 \mathrm{~m} / \mathrm{s}^{2}$, respectively. Figure $6(\mathrm{~b})$ shows the three seismic time history waves $(21,22$, and 23$)$ of large earthquakes, with a peak acceleration value of $1.542 \mathrm{~m} / \mathrm{s}^{2}$, $1.548 \mathrm{~m} / \mathrm{s}^{2}$, and $1.545 \mathrm{~m} / \mathrm{s}^{2}$, respectively. The maximum values of the seismic response of the bridge obtained from the time history analysis with the three seismic waves were 


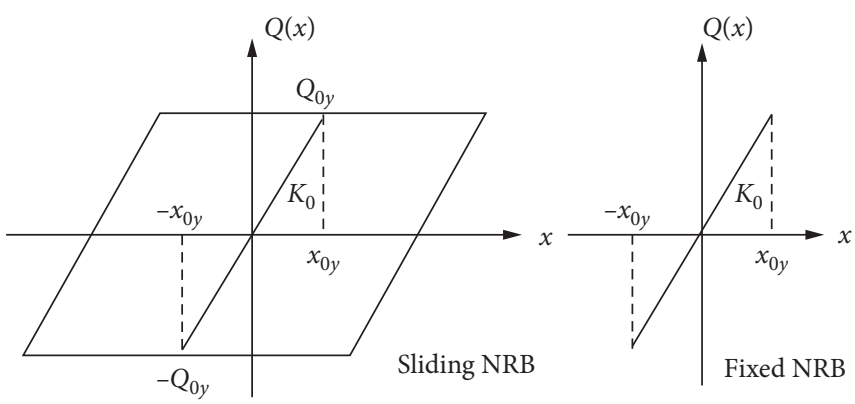

(a)

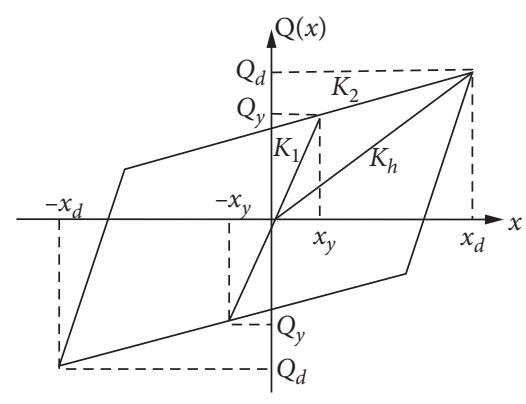

(b)

FIGURE 5: Layout and restoring force model of bearings: (a) restoring force model of NRB; (b) bilinear restoring force model of LRBs and HDRBs.

TABLE 1: Case setting of bearings.

\begin{tabular}{llllllll}
\hline \multicolumn{2}{c}{ Cases } & 1 & 2 & 3 & 4 & 5 & 6 \\
\hline Pier Nos. & No. 1, No. 4 & - & NRB-1 & LRB-1 & NRB-1 & NRB-1 & HDRB-1 \\
Pier Nos. & No. 2, No. 3 & - & NRB-2 & LRB-2 & LRB-2 & HDRB-2 & HDRB-2 \\
\hline
\end{tabular}

used to be discussed (according to the Chinese code JTG/ T B02-01-2008) [34, 50].

\section{Verification}

The verification of a mathematical model is a key step for the simulation research $[55,56]$. The shaking table test in reference [57] was analyzed by numerical simulation in this paper, in order to verify the correctness of the numerical model adopted in this paper. A two-span simply supported bridge model was built, as shown in Figure 7(a), with a $30 \mathrm{~m}$ long span and an 880 ton girder. All of the pier columns were the same height $(8 \mathrm{~m})$ and diameter $(1.6 \mathrm{~m})$. Circular laminated-rubber bearings with the diameter of $600 \mathrm{~mm}$ were used to support the beam. The specified yield strength of the steel reinforcement used in the model was $335 \mathrm{MPa}$, and that of the concrete was $40 \mathrm{MPa}$. The scale model for the shaking table test is shown in Figure 7(b), with the scale of $1 / 4$ to the prototype bridge. The column diameter and the clear height of the piers were $0.4 \mathrm{~m}$ and $2 \mathrm{~m}$, respectively. The Northridge earthquake recorded by the New Hall Fire Station with a peak acceleration of $0.59 \mathrm{~g}$ was used to analyze the seismic response of the bridge. The peak ground accelerations of ground motions were applied in increasing earthquake intensity, varying from 0.1 to $0.6 \mathrm{~g}$. The displacement of the bearings was measured by the shaking table test, as shown in Figure $7(\mathrm{c})$.

The results show that under the action of earthquakes, the trend of the analytical bearing displacements is consistent with that of the experimental displacements, as can be seen in Figure $7(\mathrm{~d})$. Figure $7(\mathrm{e})$ further presents the displacement errors in different intensities of the Northridge earthquake and shows that the errors between the analytical results and the experimental results are less than 13\%, which meets the requirement for accuracy in this study $[58,59]$. The difference may be due to the measuring instrument used for the test, which cannot achieve accurate simulation in numerical analyses [4].

\section{Analysis of the Results}

\subsection{Seismic Response of the Bridge}

6.1.1. Displacement of the Bearings. Rubber bearings of bridges deform and thereby reduce the seismic load onto the structure in an earthquake, and their deformation capacity and hysteretic deformation under the action of earthquakes can directly reflect their aseismic effect. Figure 8 shows the displacement of the bearings at each pier in different cases under the action of small and large earthquakes. On the whole, the No. 1 and No. 4 piers have much higher bearing displacements than the No. 2 and No. 3 piers; the No. 3 pier basically has the same bearing displacements as the No. 2 pier in different cases; the displacement of the bearings under the action of large earthquakes is about 8 times that under the action of small earthquakes.

Figures 8(a) and 8(c) show the longitudinal displacement of each bearing under the action of small and large earthquakes, respectively. The displacement of the bearings of the different piers changes in the same trend. The displacement of the bearings of the No. 1 pier is larger; that at the No. 2 pier decreases and is close to that of the No. 3 pier; and that of the No. 4 pier increases and is close to that of the No. 1 pier. The bearing displacement of the No. 1 and No. 4 piers is generally larger than that of the No. 2 and No. 3 piers mainly due to the larger stiffness of the bearings of the No. 2 and No. 3 piers. However, the maximum displacement of the bearings under the action of large earthquakes is $42.09 \mathrm{~cm}$ in Case 2, which exceeds the limiting deformation of NRB-1. In several cases, the displacement of the bearings of the No. 1 and No. 4 piers exceeds the ultimate displacement, meaning that damage has occurred to the bearings. Under the action of small earthquake and large earthquakes, the bearings have the maximum displacement in Case 1. In Case 3, the longitudinal displacement 
TABLE 2: Physical parameters of bearings.

\begin{tabular}{|c|c|c|c|c|c|c|}
\hline Bearings & NRB-1 & NRB-2 & LRB-1 & LRB-2 & HDRB-1 & HDRB-2 \\
\hline Height of bearings (mm) & 96 & 112 & 154 & 234 & 137 & 187 \\
\hline Total thickness of rubber layer $(\mathrm{mm})$ & 67 & 82 & 76 & 125 & 70 & 110 \\
\hline Vertical bearing force $(\mathrm{kN})$ & 1258 & 2701 & 1417 & 3510 & 1360 & 3489 \\
\hline Vertical stiffness, $K_{v}(\mathrm{kN} / \mathrm{m})$ & 689183 & 1168633 & 806791 & 1382812 & 875000 & 1427000 \\
\hline Preyield stiffness, $K_{1}(\mathrm{kN} / \mathrm{m})$ & - & - & 7225 & 12810 & 4690 & 7510 \\
\hline Postyield stiffness, $K_{2}(\mathrm{kN} / \mathrm{m})$ & - & - & 1133 & 1930 & 1340 & 2150 \\
\hline Equivalent stiffness, $K_{0}, K_{h}(\mathrm{kN} / \mathrm{m})$ & 1700 & 2720 & 1700 & 2720 & 1700 & 2720 \\
\hline Yield force, $Q_{0 y}, Q_{y}(\mathrm{kN})$ & 25 & - & 106 & 190 & 53 & 133 \\
\hline Shear modulus, $G(\mathrm{MPa})$ & 1.0 & 1.0 & 1.0 & 1.0 & 1.0 & 1.0 \\
\hline Damping ratio, $\xi(\%)$ & - & - & 19.1 & 16.7 & 12 & 12 \\
\hline Limiting displacement (mm) & 90 & 150 & 227 & 376 & 210 & 330 \\
\hline
\end{tabular}
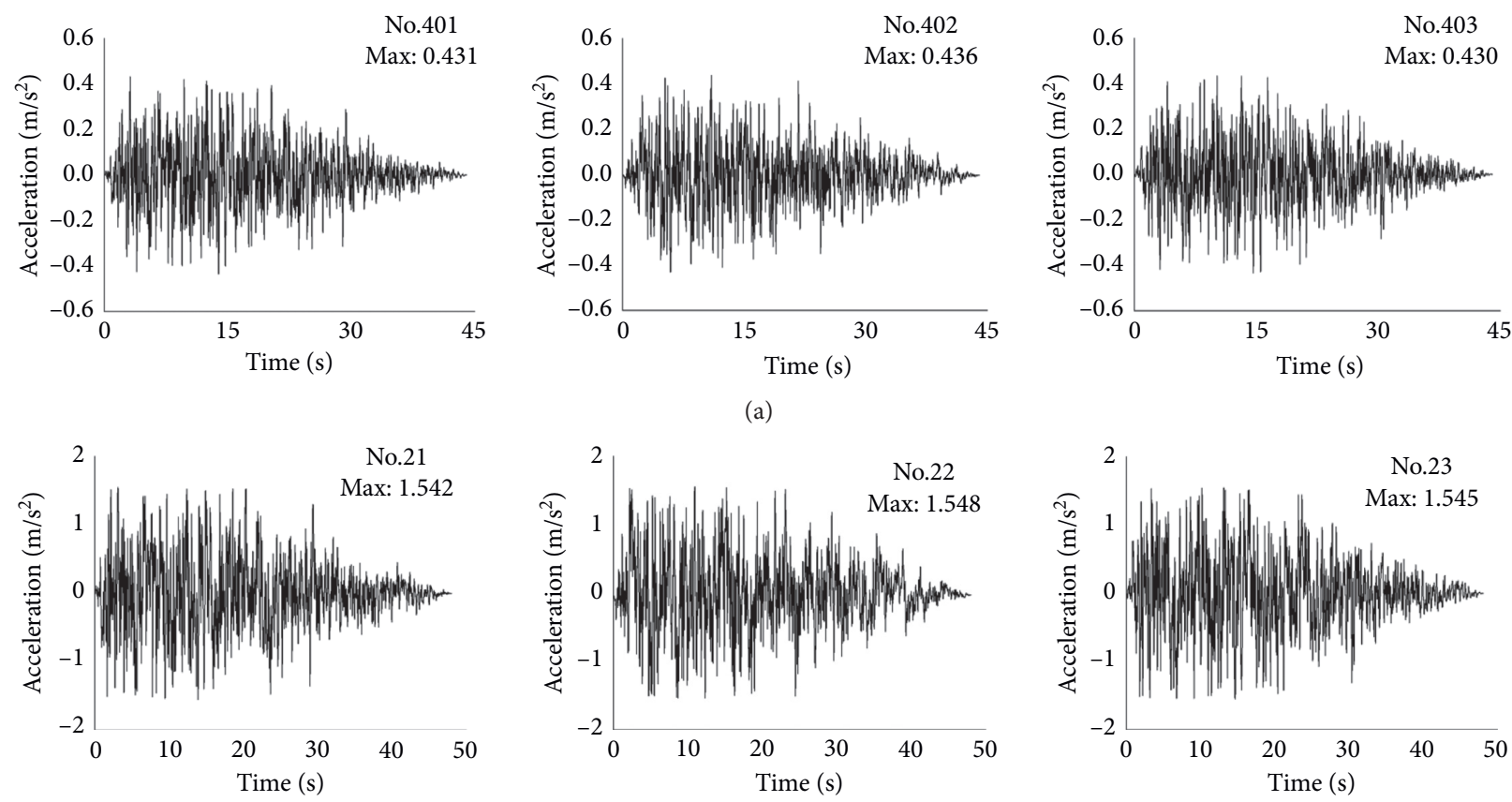

(b)

Figure 6: Time history and acceleration response spectrum of the earthquakes: (a) time history of the small earthquakes; (b) time history of the large earthquakes.

of each bearing is approximately $30 \%$ and $60 \%$ of maximum displacement under small and large earthquakes, respectively. In Case 5, the longitudinal displacement of each bearing is approximately $50 \%$ and $65 \%$ of the maximum displacement under the action of small and large earthquakes, respectively.

Figures 8(b) and 8(d) show the lateral displacement of each bearing under the action of small and large earthquakes, respectively. In different cases, the No. 1 and No. 4 piers have larger displacement of their bearings, while the No. 2 and No. 3 piers have similar displacement of their bearings, which is lower than that of the No. 1 and No. 4 piers. Under the action of small earthquake and large earthquakes, the bearings have maximum displacement in Case 2, which is much larger than that in other cases. The displacement of the bearings exceeds the limiting displacements under the action of large earthquake in Case 2, indicating that damage has occurred to bearings under the action of earthquake. In Case 3, the lateral displacement of each bearing is approximately $30 \%$ and $40 \%$ of the maximum displacement under the action of small and large earthquakes, respectively. In Case 5, the lateral displacement of each bearing is approximately $35 \%$ and $45 \%$ of the maximum displacement under the action of small and large earthquakes, respectively.

In Cases 4 and 6, both the longitudinal and the lateral displacements of the bearings of the No. 1 and No. 4 piers are almost 2 times than those of the No. 2 and No. 3 piers under the action of small earthquakes due to the preyield stiffness of the bearings of the latter two piers being much larger than the NRBs of the former two piers. The displacements of NRB-1 exceed the limiting displacements under the action of large earthquakes in Cases 4 and 6. In Cases 3 and 5, as LRBs and HDRBs were set on all of the piers, the longitudinal and lateral bearing displacements under the action of earthquakes are smaller than in the other cases. The displacements of the LRBs and HDRBs are within the limiting 


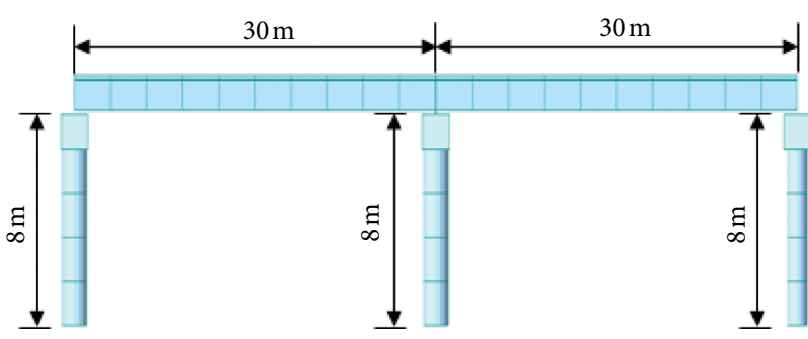

(a)

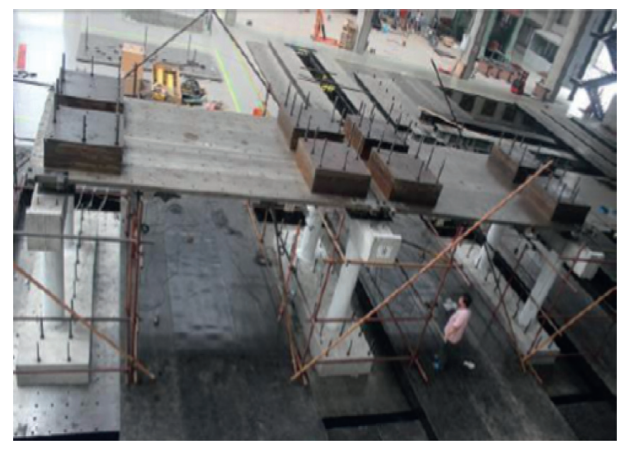

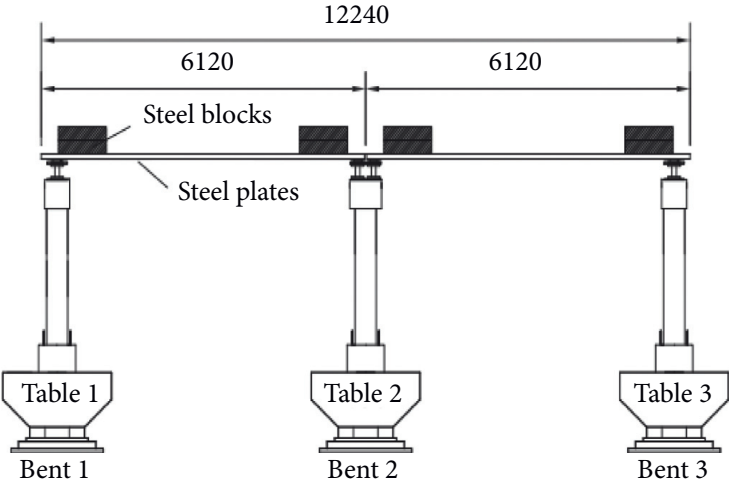

(b)

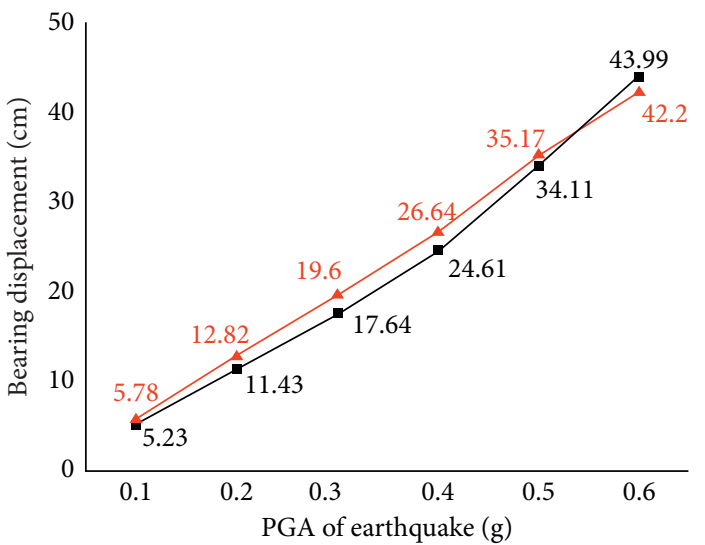

$\rightarrow$ Experimental

- Analytical

(d)

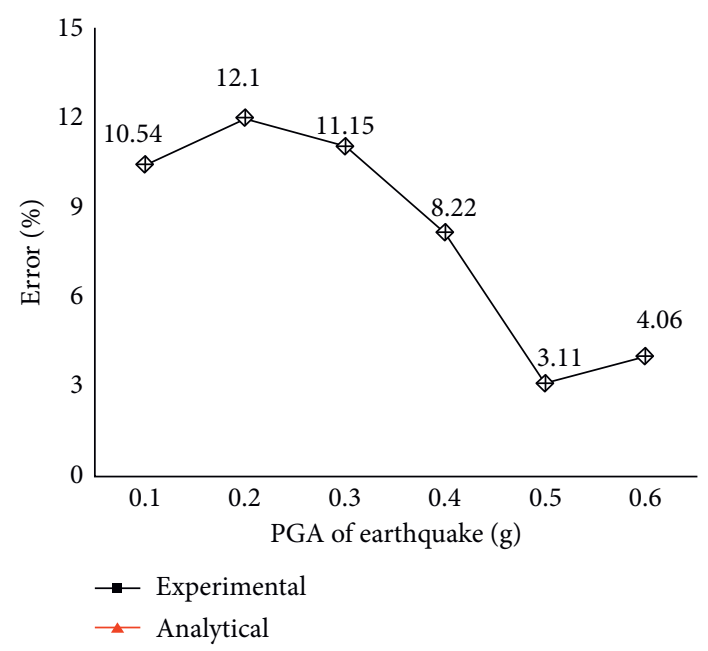

(e)

FIGURE 7: Models and results: (a) analytical model; (b) experimental model; (c) model for the shaking table test; (d) seismic response under different intensities of Northridge earthquake; (e) error analysis of the test and numerical simulation. 
displacements under the action of large earthquake. Moreover, according to the pushover analysis results, the LRBs and HDRBs do not yield under the action of large earthquakes.

6.1.2. Hysteresis Curve of the Bearings. The hysteretic curve can characterize the deformation and energy characteristics of isolation bearings. Figure 9 shows the hysteretic curves of the LRBs and HDRBs of the No. 2 pier in different cases under the action of the small earthquake (401) and the large earthquake (23). The mechanical properties of the LRBs and HDRBs were nonlinear, as the horizontal seismic force at the bearings exceeds their yield force, and thus the bearings yield and dissipate seismic energy.

Figure 9(a) shows the hysteretic curves of the LRB-2 bearings of the No. 2 piers under the action of small and large earthquakes in Case 3. The hysteretic curves of LRB-2 in Case 3 are different under the action of small and large earthquakes. The LRB-2 bearings of the No. 2 pier have the maximum displacement of $1.17 \mathrm{~cm}$ and $22.26 \mathrm{~cm}$ and the maximum horizontal shear force of $121 \mathrm{kN}$ and $572 \mathrm{kN}$ under the action of small and large earthquakes, respectively. As the bearings never yield under the action of small earthquakes, the energy consumption is less $(63,154 \mathrm{~kJ})$, while the bearings yield under the action of large earthquakes and play a great role in the aseismic effect and energy consumption, with an energy consumption of $3,903,502 \mathrm{~kJ}$.

Compared to Case 3, the hysteretic curves of LRB-2 in Case 4 under the action of small and large earthquakes are plumper. The LRB-2 bearings of the No. 2 pier have a maximum displacement of $1.47 \mathrm{~cm}$ and $28 \mathrm{~cm}$, a maximum horizontal shear force of $149 \mathrm{kN}$ and $683 \mathrm{kN}$, and an energy consumption of $94,186 \mathrm{~kJ}$ and $6,473,746 \mathrm{~kJ}$ under the action of small and large earthquakes, respectively. It can be seen from Figures 9(a) and 9(b) that the bearings of the No. 2 pier in Case 4 have larger (approximately 1.5 times) displacement, horizontal shear force, and energy consumption than those in Case 3 mainly because the bearings (NRB-1) of the No. 1 and No. 4 piers in Case 4 have much smaller stiffness and thereby larger shear deformation than the bearings (LRB-1) in Case 3 under the action of earthquakes.

Figures 9(c) and 9(d) show the hysteretic curves of HDRB-2 of the No. 2 piers under the action of small and large earthquakes in Cases 5 and 6, respectively. The HDRB-2 bearings of the No. 2 pier in Case 5 have a maximum displacement of $1.81 \mathrm{~cm}$ and $25 \mathrm{~cm}$, a maximum horizontal shear force of $110 \mathrm{kN}$ and $633 \mathrm{kN}$, and an energy consumption of $121,453 \mathrm{~kJ}$ and $548,017 \mathrm{~kJ}$ under the action of small and large earthquakes, respectively. In Case 6, the HDRB-2 bearings have a maximum displacement of $2.68 \mathrm{~cm}$ and $30.2 \mathrm{~cm}$, a maximum horizontal shear force of $146 \mathrm{kN}$ and $744 \mathrm{kN}$, and an energy consumption of $126,942 \mathrm{~kJ}$ and $8,629,838 \mathrm{~kJ}$ under the action of small and large earthquakes, respectively. The bearings of the No. 2 pier in Case 6 have larger (approximately 1.3 times) displacement, horizontal shear force, and energy consumption than those in Case 5, which are slightly larger than those in Case 4. This indicates that the LRBs in Case 4 have a better isolation effect than the HDRBs in Case 3.

6.1.3. Bending Moment of the Bottom of the Piers. The bending moment of a pier affects the seismic safety of the substructure of a bridge under the action of earthquakes. Theoretically, a smaller bending moment of the bottom of a pier leads to a higher seismic safety of the said pier. Figure 10 shows the bending moments of the bottom of the piers in the longitudinal and lateral directions of the bridge with different bearings under the action of small and large earthquakes. Figure 10(a) shows the bending moments of the bottom of the piers in the longitudinal direction of the bridge in different cases under the action of small earthquake. In Case 1, the change trend of the bottom bending moments of the four piers is similar to the displacement of the top of the piers. The No. 1 and No. 4 piers have maximum bending moments of their bottoms of $58,836 \mathrm{kN} \cdot \mathrm{m}$ and $58,696 \mathrm{kN} \cdot \mathrm{m}$ in Case 1, respectively. In the other cases, the No. 2 and No. 3 piers have higher bending moments of the bottom of the piers than the No. 1 and No. 4 piers. In Case 2, the four piers have the lowest bending moments of their bottoms; in Cases 4 and 6, the bending moments of the bottom of the No. 2 and No. 3 piers are almost 1.6 times bigger than those of the No. 1 and No. 4 piers. In Cases 3 and 5, the bending moments of the bottom of the piers are relatively small. Figure 10(b) shows that, in different cases, the bending moments of the bottom of the piers have similar trends, and the No. 2 and No. 3 piers have bigger bending moments of the pier bottoms than the No. 1 and No. 4 piers. In Case 1, the four piers have the biggest bending moments of their bottoms. In Cases 4 and 6, the No. 1 and No. 4 piers have almost 1.8 times bigger bending moments than the No. 2 and No. 3 piers. Due to the fact that the NRBs of the No. 1 and No. 4 piers have smaller stiffness and that the HDRBs of the No. 2 and No. 3 piers have higher stiffness, more seismic loads are transmitted to the No. 2 and No. 3 piers. The piers have smaller bending moments of their bottoms in Case 5, meaning that the HDRBs show a relatively better isolation effect under the action of small earthquake.

Figure 10(c) shows the longitudinal bending moment of the bottom of the piers under the action of large earthquakes. The bending moment increases first and then decreases in different cases. The bending moments of the bottoms of the different piers with LRBs and HDRBs (Cases 3-6) are similar and smaller than those with NRBs (Case 2). The bending moments of the bottom of the piers in Cases 3 and 5 are approximately $60 \%$ and $70 \%$ of those in Case 2, meaning that the LRBs and HDRBs have good aseismic effect and reduce the seismic load of the bridge, especially under the action of large earthquake. Although the same bearings were used for the No. 2 and No. 3 piers in Cases 3 and 4 , the piers have bigger bending moments of their bottoms in Case 4 than in Case 3 . The piers have almost 


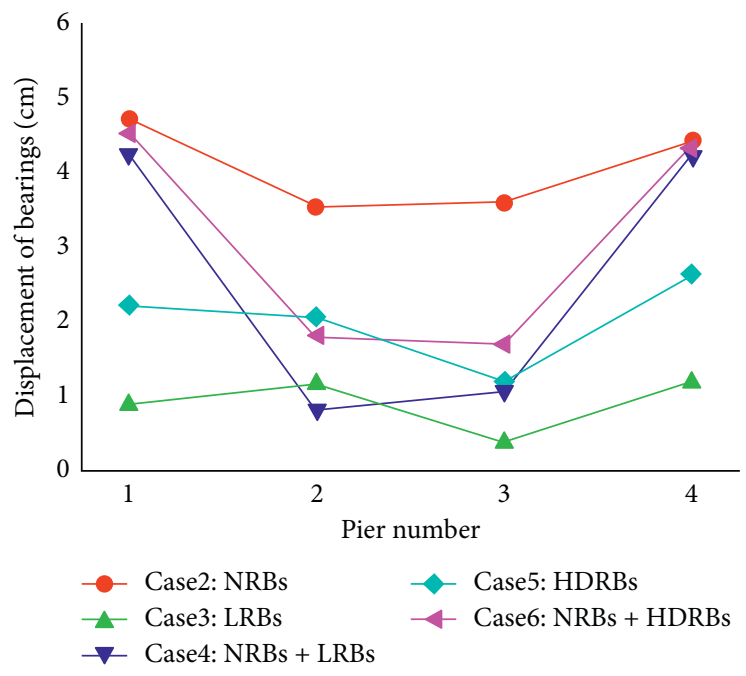

(a)

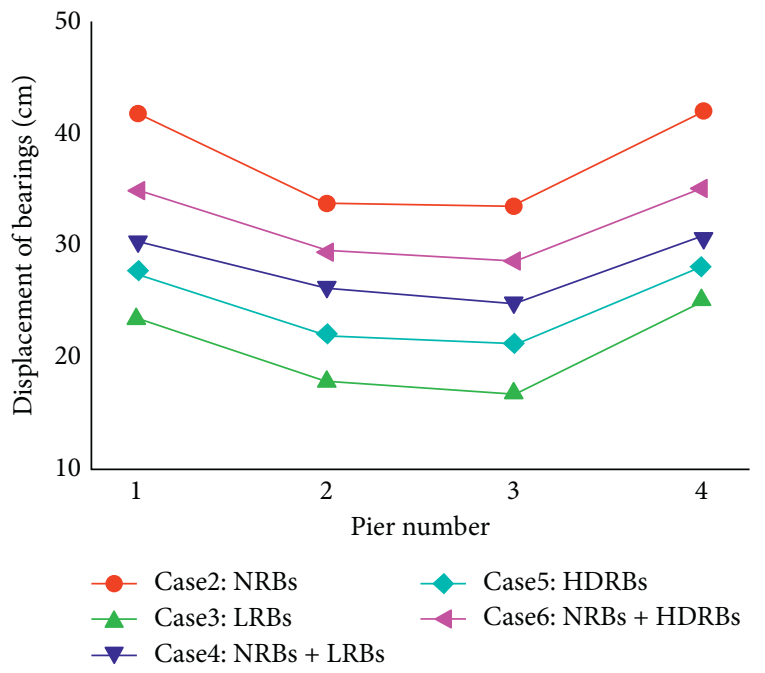

(c)

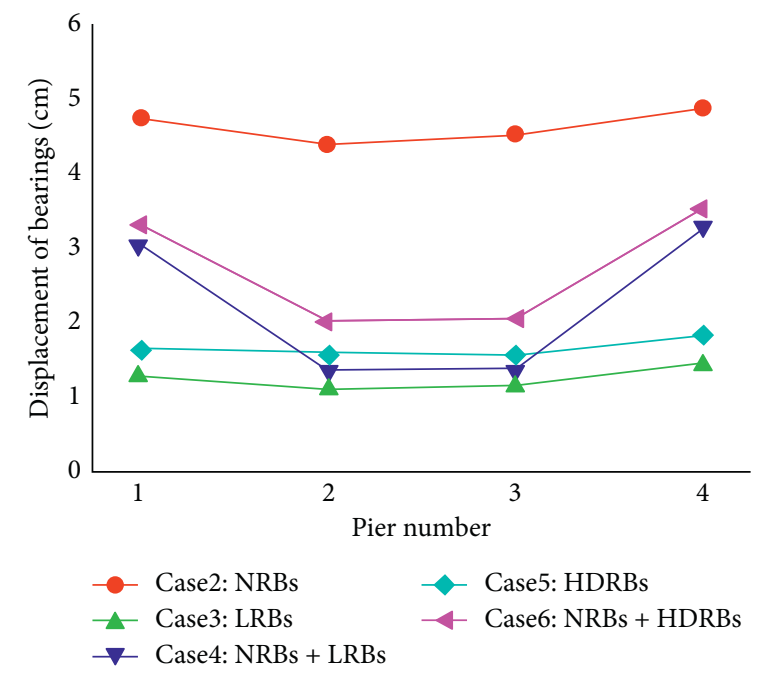

(b)

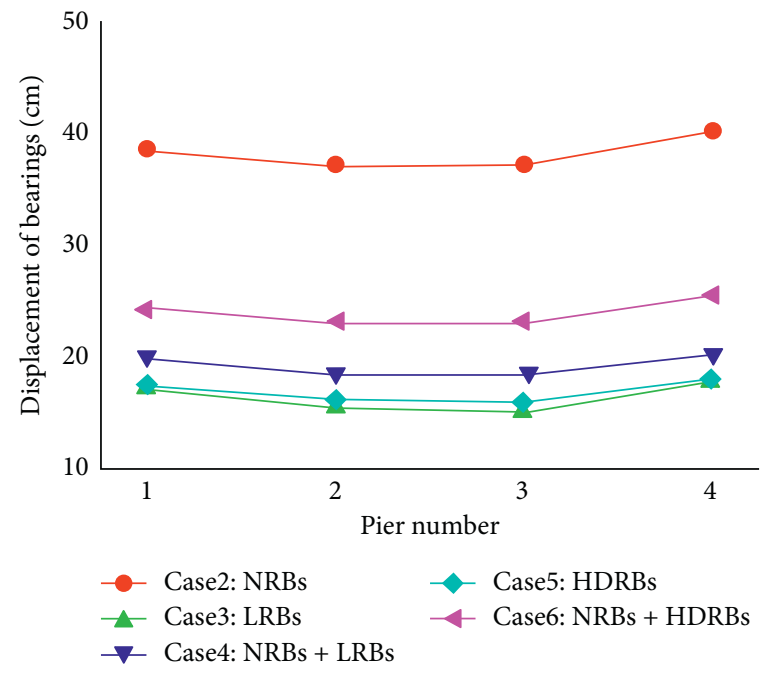

(d)

Figure 8: Displacement of bearings in different cases: (a) longitudinal displacement under the action of small earthquake; (b) lateral displacement under the action of small earthquake; (c) longitudinal displacement under the action of large earthquake; (d) lateral displacement under the action of large earthquake.

minimum bending moments of their bottoms in Case 1, and the bending moments of the bottom of the piers exceed the yield moment $(292,468 \mathrm{kN} \cdot \mathrm{m})$ in Cases 1 and 2 . Figure $10(\mathrm{~d})$ shows the bending moments of the bottom of the piers in the lateral direction of the bridge under the action of large earthquake. The lateral bending moments of the bottom of the piers are almost the biggest in Cases 1 and 2. The other piers have smaller bending moments of their bottoms in the lateral directions of the bridge. The bending moments of the bottom of the piers in Cases 3 and 5 are almost $60 \%$ of that without bearings (Case 1). The bottom bending moments of the No. 2 and No. 3 piers exceed the yield moment in Cases 1 and 2, indicating that the use of isolation bearings can prevent the piers from being damaged under the action of large earthquakes.
According to the static elastoplastic pushover analysis results, the bottoms of the piers have lower longitudinal and lateral bending moments than maximum bending yield strength in different cases under the action of large earthquake.

6.1.4. Shear Force of the Bottom of the Piers. Figure 11 shows the shear forces of the bottom of the piers in the longitudinal and lateral directions of the bridge with different bearings under the action of small and large earthquakes, respectively. Figure 11(a) shows that in Case 1, No. 2 and No. 3 piers have smaller shear force of their bottoms than the No. 1 and No. 4 piers, and the piers have the maximum shear force of their bottoms in Case 1. In the other cases, the No. 2 and No. 3 piers have bigger shear force of their bottoms than the No. 1 

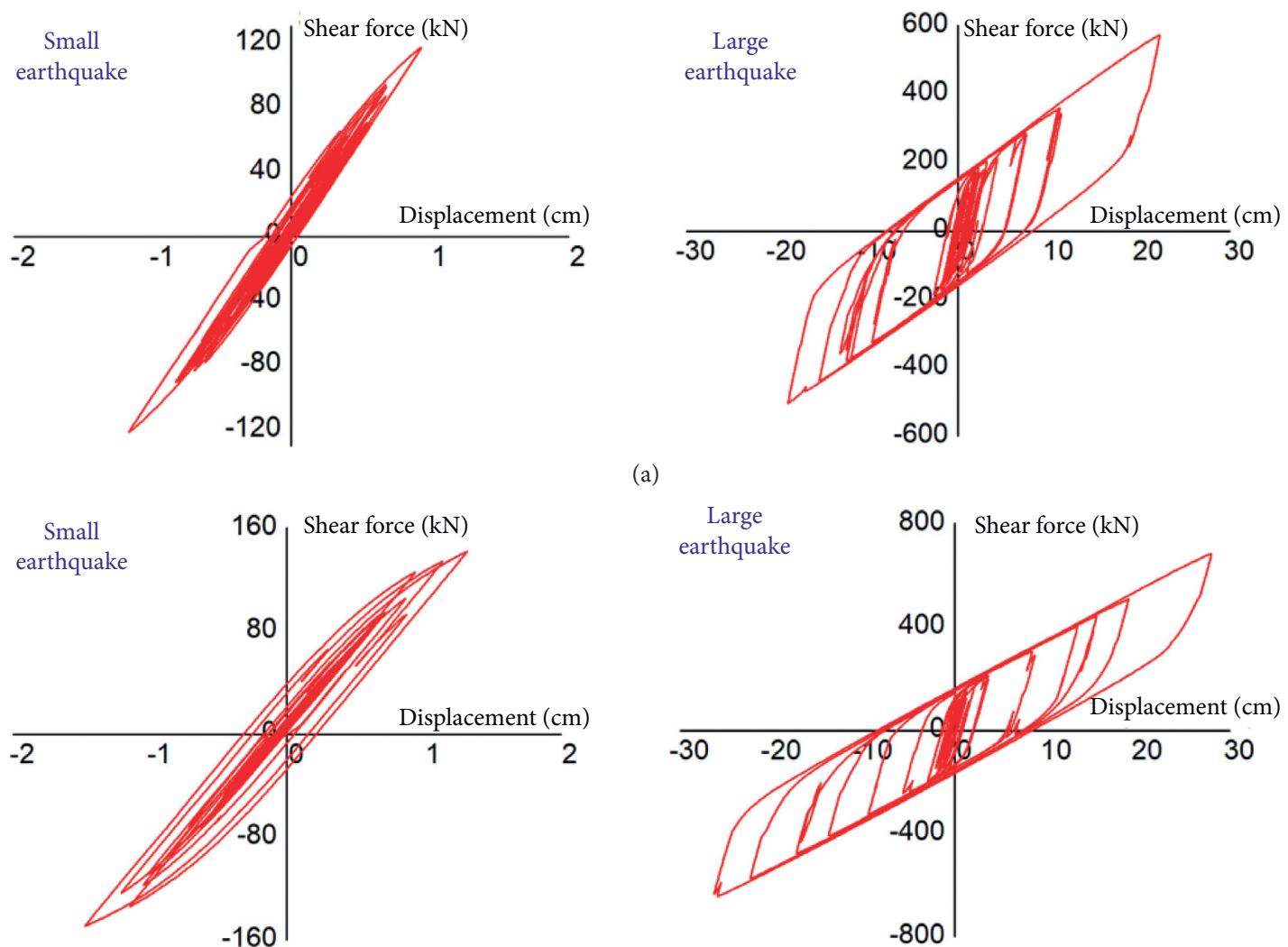

(a)
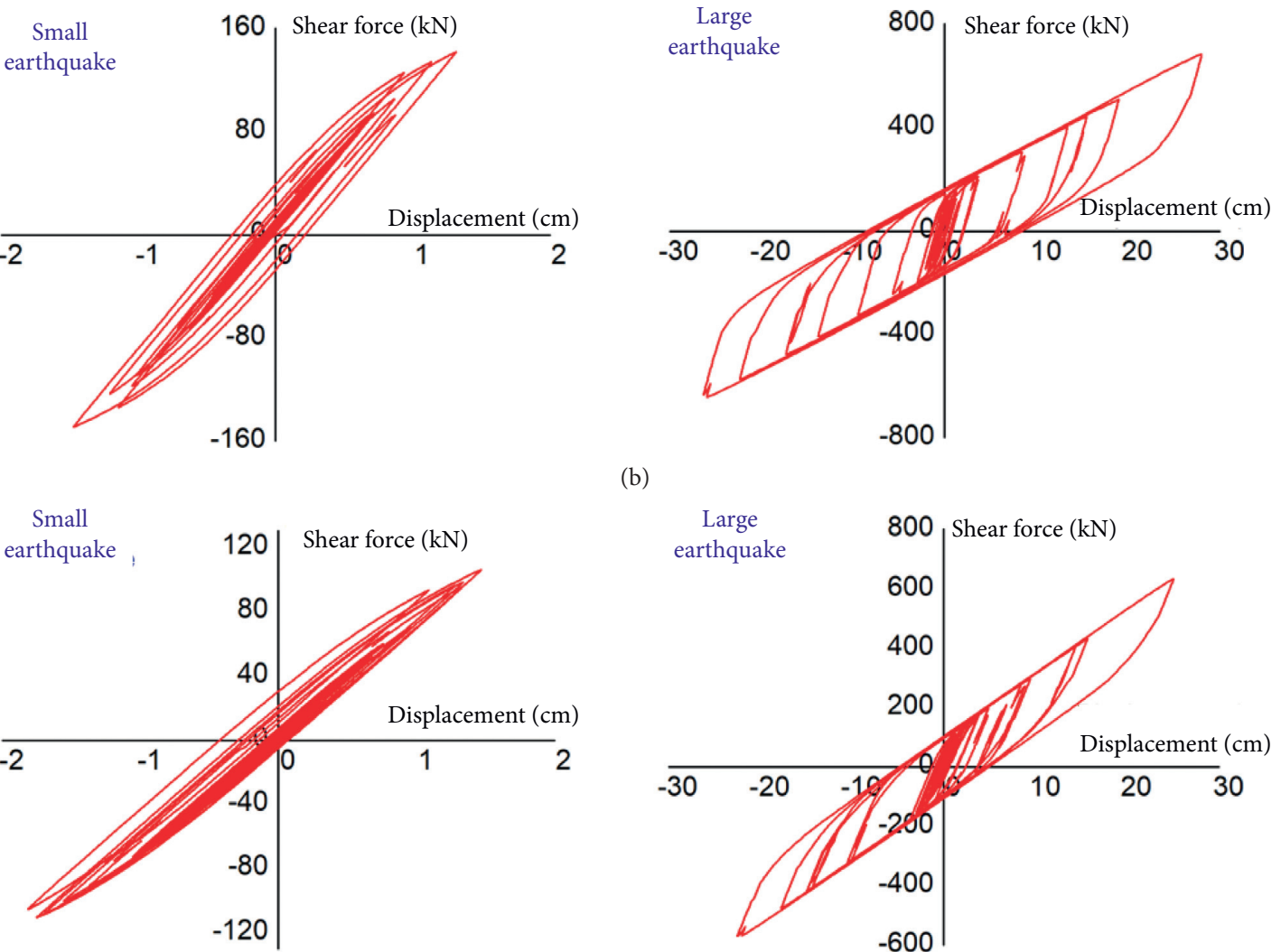

(b)
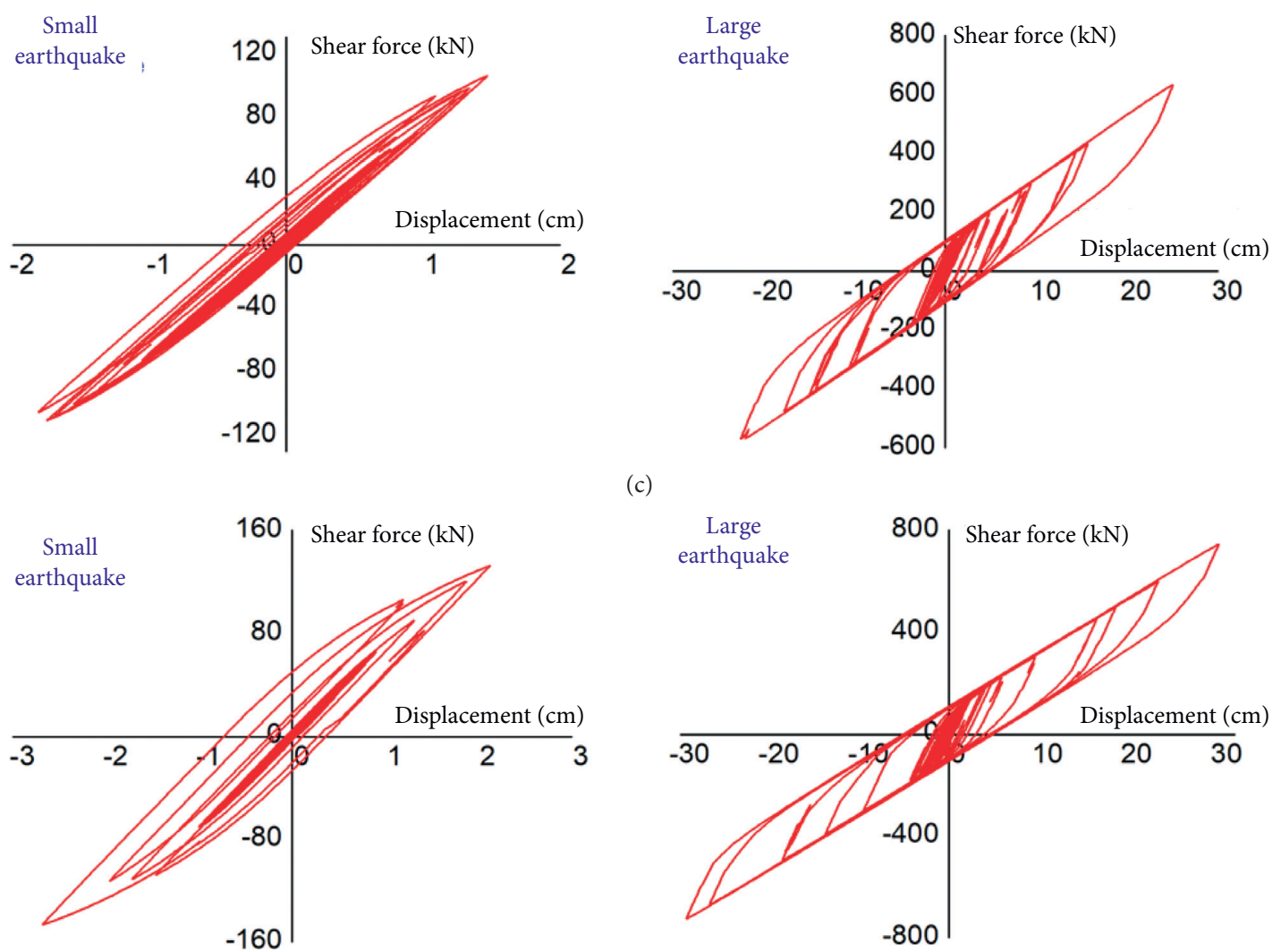

(c)

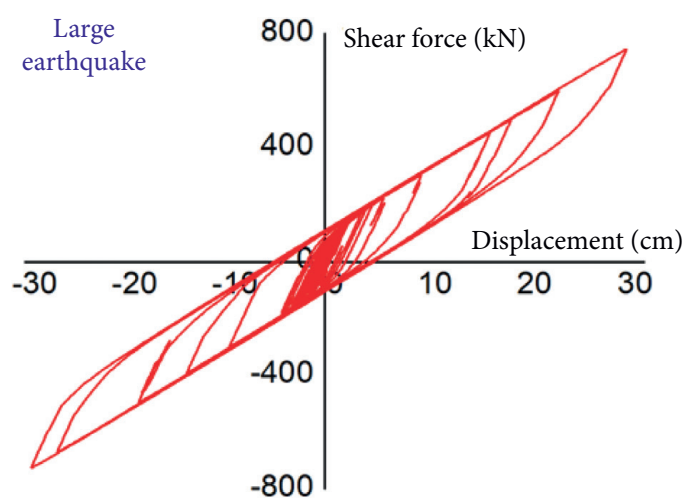

(d)

Figure 9: Hysteresis curve of bearings of the No. 2 pier: (a) LRB-2 in Case 3; (b) LRB-2 in Case 4; (c) HDRB-2 in Case 5; (d) HDRB-2 in Case 6. 


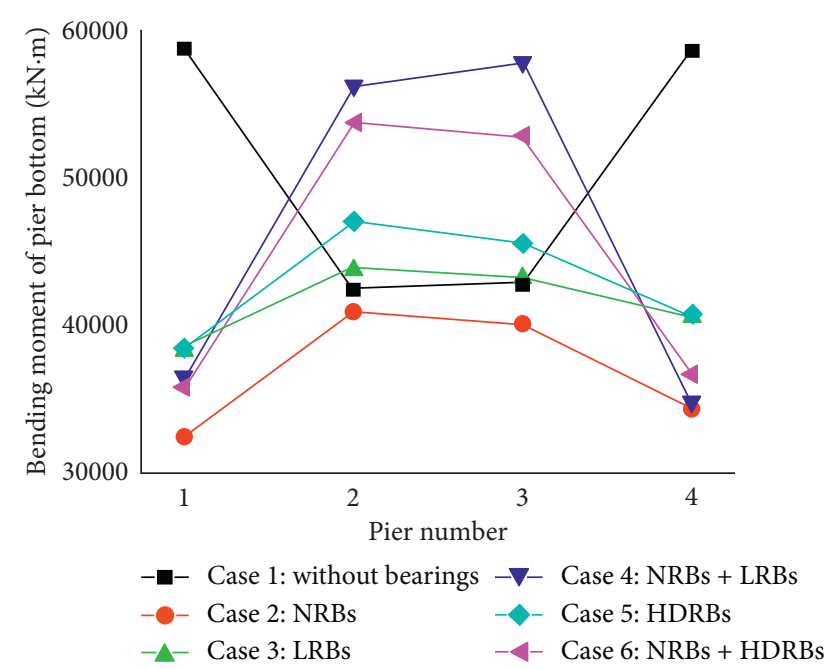

(a)

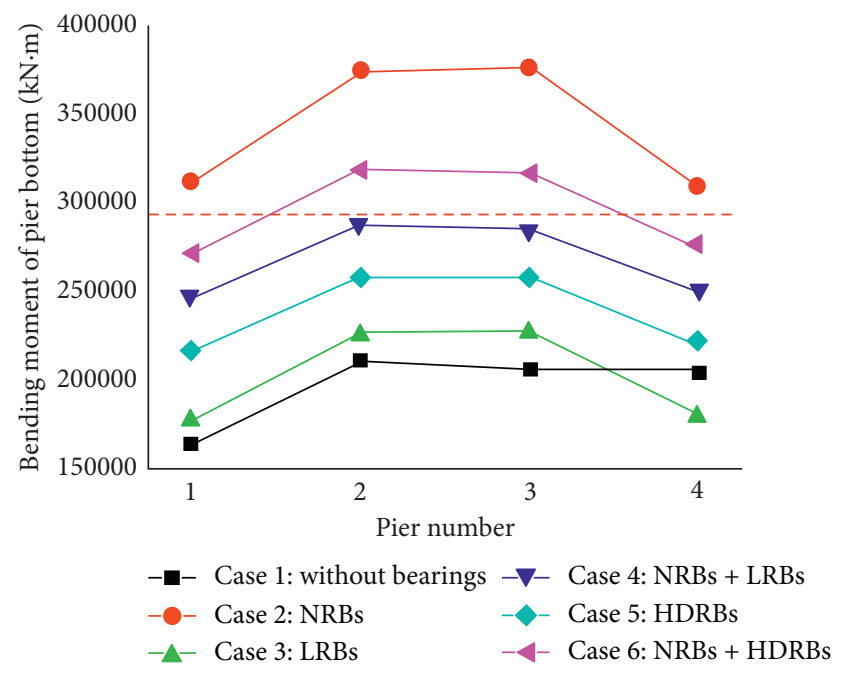

(c)

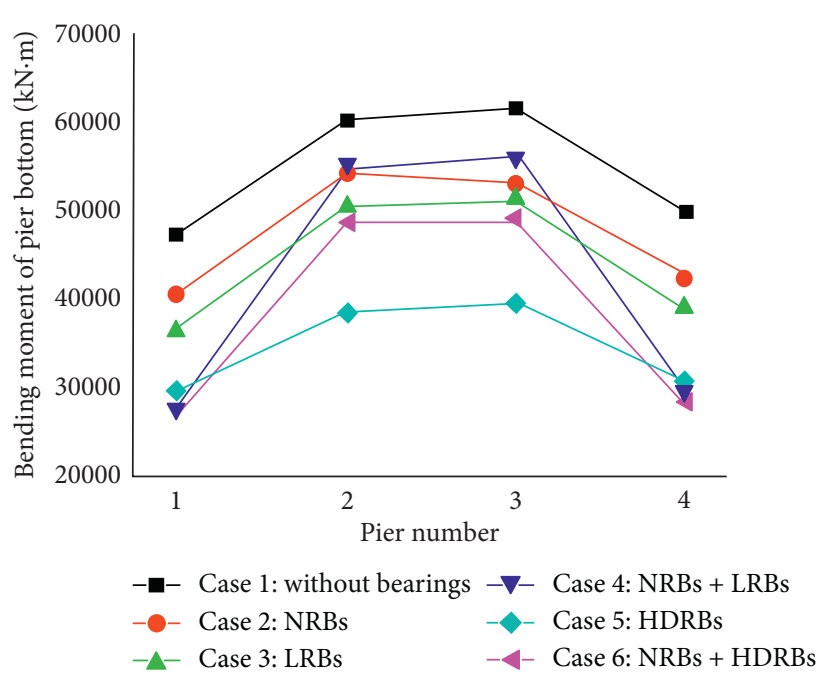

(b)

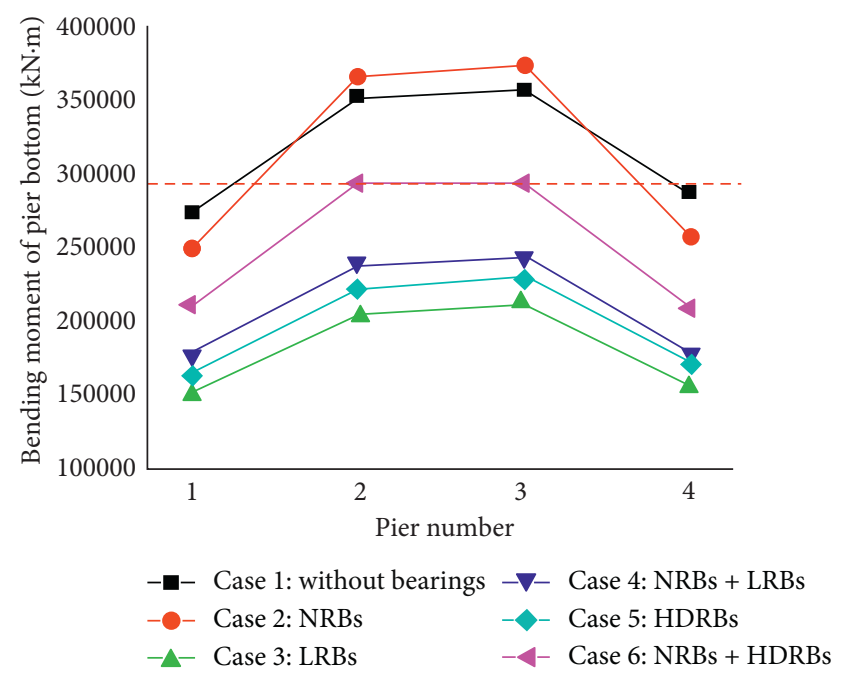

(d)

FIGURE 10: Bending moments of the bottom of the pier in different cases: (a) longitudinal moment under the action of small earthquake; (b) lateral moment under the action of small earthquake; (c) longitudinal moment under the action of large earthquake; (d) lateral moment under the action of large earthquake.

and No. 4 piers. The piers have smaller shear force of their bottoms in Case 2, which is approximately $60 \%$ of maximum shear force of the bottom of the piers in Case 1. Figure 11(b) shows the shear force of the bottom of the piers in the lateral direction of the bridge under the action of small earthquakes. In different cases, the shear force of the bottom of the piers increases first and then decreases in different cases. The overall shear force of the bottom of the piers is bigger in Case 1 and smaller in Case 5. The No. 2 and No. 3 piers have bigger shear force of their bottoms than the No. 1 and No. 4 piers in Cases 4 and 6 due to the fact that the LRBs and HDRBs do not yield under the action of small earthquakes and have bigger preyield stiffness than the NRBs in Case 2.

Figure 11(c) shows the shear force of the bottom of the piers in the longitudinal direction of the bridge under the action of large earthquakes. The shear force of the bottoms of the four piers in Case 2 is $6821 \mathrm{kN}, 7883 \mathrm{kN}, 7947 \mathrm{kN}$, and $6927 \mathrm{kN}$, respectively, bigger than that of the corresponding piers in the other cases. The shear force of the bottoms of the piers with aseismic bearings (Cases 3 and 5) is approximately $70 \%$ of that without aseismic bearings (Case 2). The shear force of the bottoms of the piers in Cases 4 and 6 is approximately $85 \%$ of that in Case 2 . Figure 11(d) shows the shear force of the bottoms of piers in the lateral direction of the bridge under the action of large earthquakes. The four piers in Case 2 have bigger shear force of their bottoms than in other cases. The piers in Case 3 have almost the smallest shear force of their bottoms, which is $65 \%$ of the shear force of those in Case 2; the shear force of the bottom of the piers in Case 1 is between that in Case 2 and Case 6. 


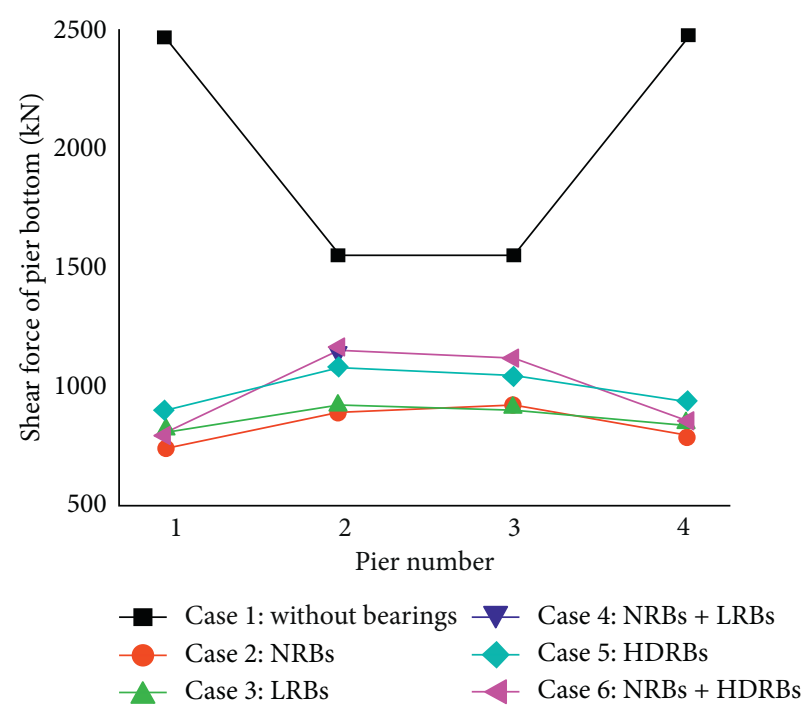

(a)

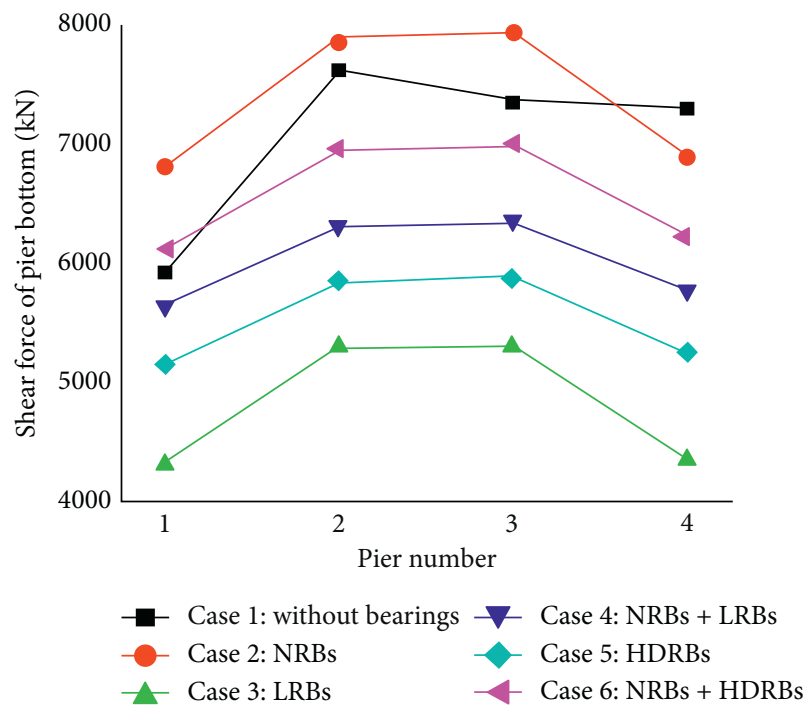

(c)

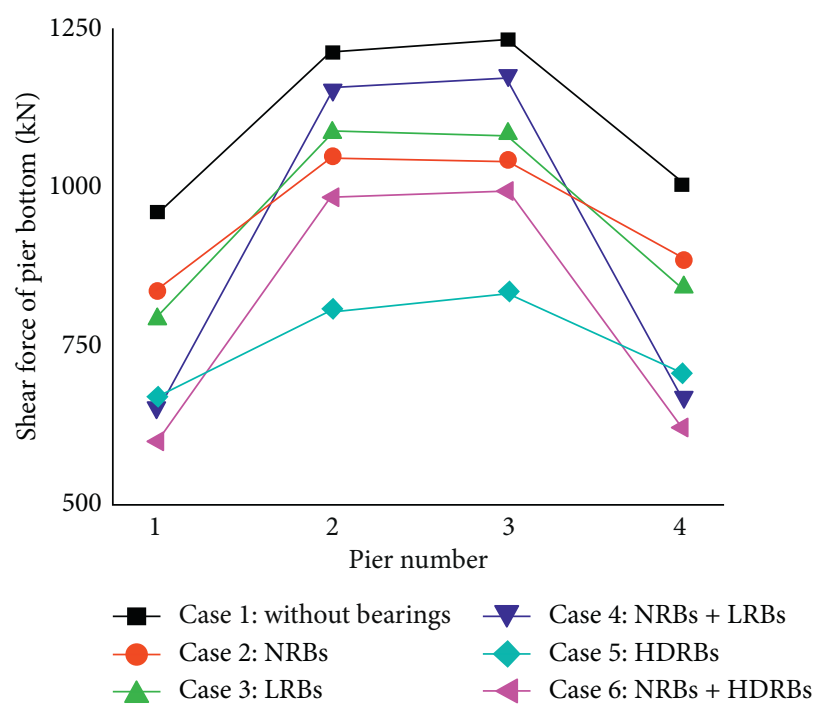

(b)

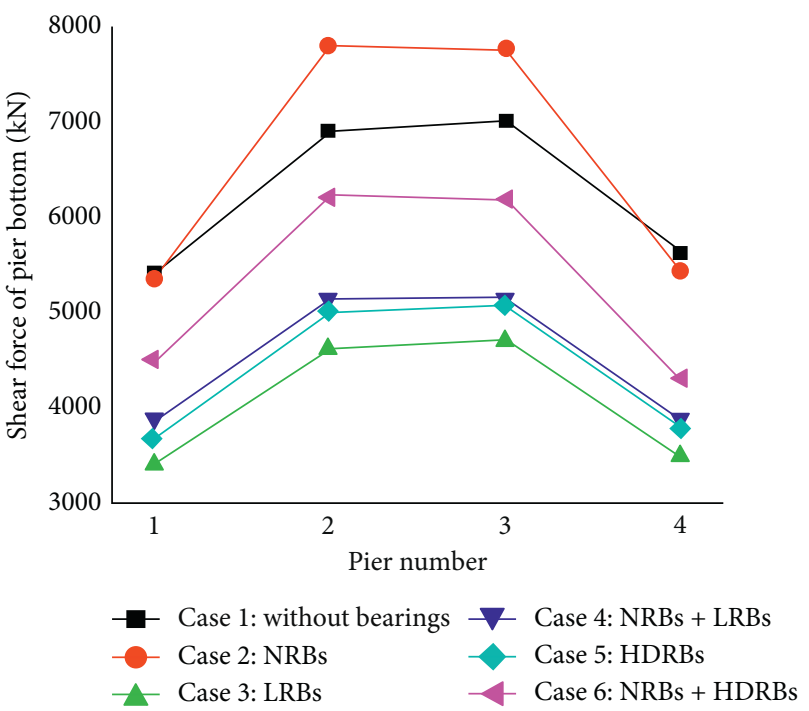

(d)

FIGURE 11: Shear force of the bottom of the piers in different cases: (a) longitudinal shear force under the action of small earthquake; (b) lateral shear force under the action of small earthquake; (c) longitudinal shear force under the action of large earthquake; (d) lateral shear force under the action of large earthquake.

In summary, the use of isolation bearings can effectively reduce the shear force of the bottom of the piers of the bridge under the action of large earthquake, meaning that the LRBs and HDRBs have a better isolation effect. Under the action of small earthquakes, the bridge structure has the biggest overall seismic response in Case 1 without bearings because the bearings deformed and created an isolation effect in the other cases. In Cases 4 and 6, the bottom shear force of the No. 1 and No. 4 piers is smaller than that in Cases 3 and 5 under the action of small earthquakes, but the shear force of the No. 2 and No. 3 piers is bigger than that in Cases 3 and 5 due to the fact that bearings of the No. 2 and No. 3 piers do not yield and have bigger preyield stiffness under the action of small earthquakes. Under the action of large earthquakes, the shear force of the bottom of the piers in Cases 4 and 6 is larger than that in Cases 3 and 5 .

It is confirmed in the conclusion of the experimental study in reference [2] that the side and middle piers of the continuous beam bridge have quite different seismic response. Only HDRBs were used for each pier to investigate the acceleration response of the bridge in their studies.

6.1.5. Displacement of the Top of the Piers. In an earthquake, a larger displacement of the top of a pier leads to greater damage to a bridge. Thus, controlling the displacement of the top of a pier in a reasonable range is important to guaranteeing the stability of a bridge. Figure 12 shows the 


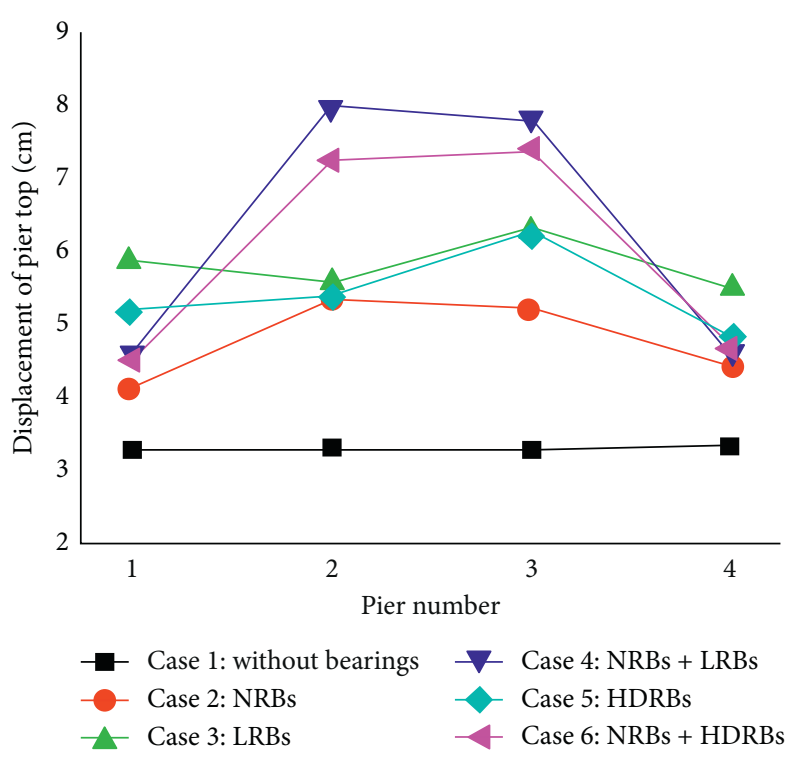

(a)

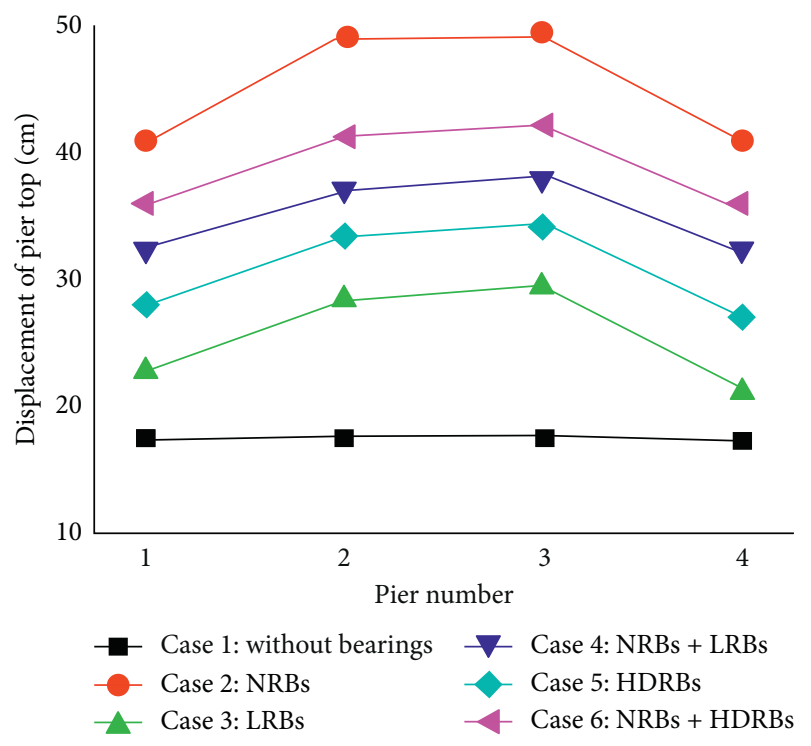

(c)

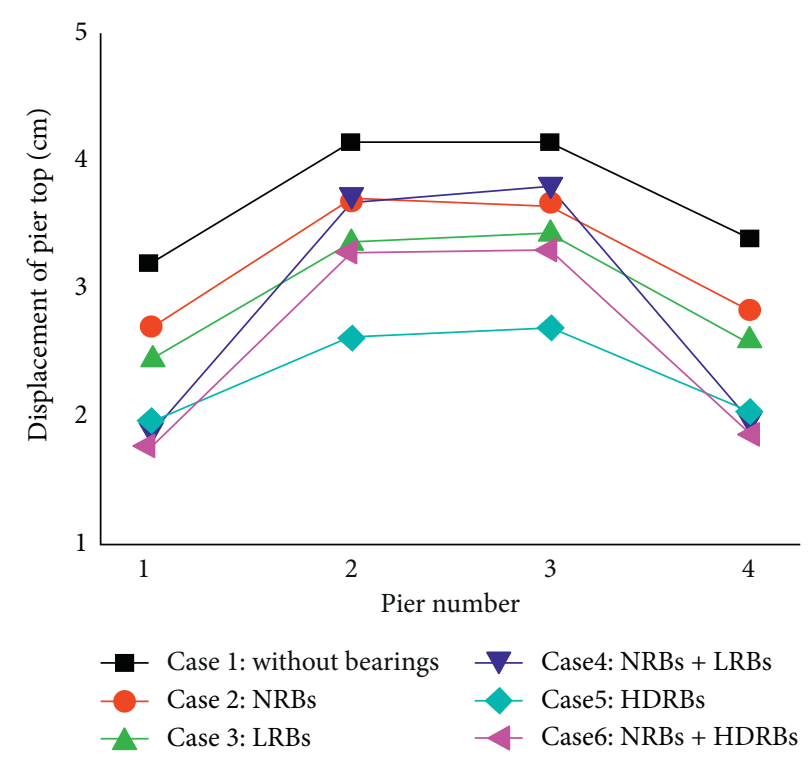

(b)

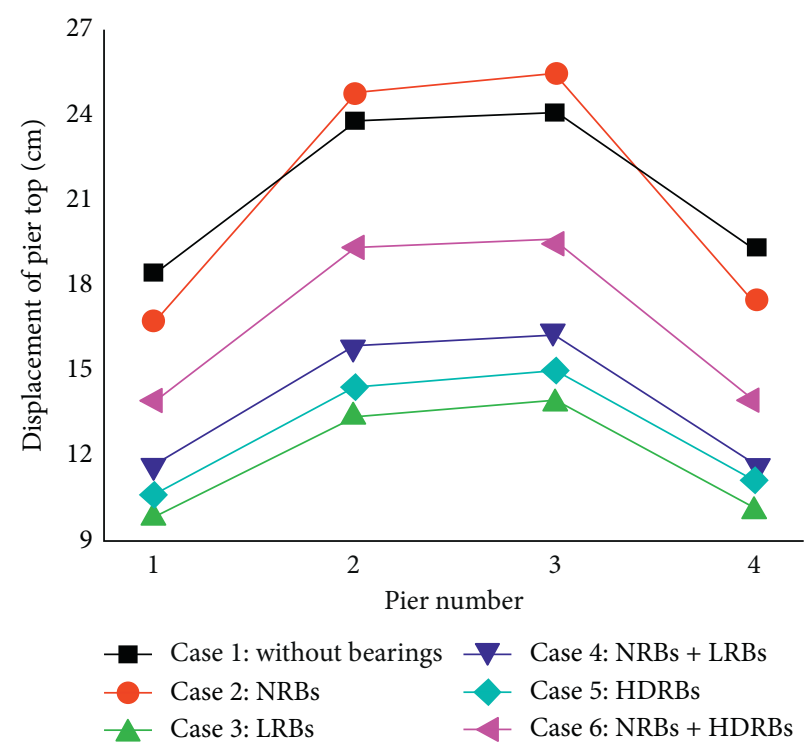

(d)

FiguRE 12: Displacement of the pier top in different cases: (a) longitudinal shear force under the action of small earthquake; (b) lateral shear force under the action of small earthquake; (c) longitudinal shear force under the action of large earthquake; (d) lateral shear force under the action of large earthquake.

displacement of the top of the piers in different cases under the action of small and large earthquakes. In the different cases, the No. 2 and No. 3 piers generally have bigger displacement of their tops than the No. 1 and No. 4 piers, and the piers at the two sides of the bridge have similar or much smaller displacement of their tops than the two piers in the middle of the bridge mainly due to the fact that the No. 2 and No. 3 piers have higher rigidity and thereby bear larger seismic load.

Figure 12(a) shows the longitudinal displacement of the top of the piers under the action of small earthquakes. The piers have the lowest displacement of their tops in Case 1, as the longitudinal stiffness of the bridge without bearings is much bigger than in other cases. The piers generally have bigger displacement of their tops in Cases 4 and 6 than in the other cases, and the No. 2 and No. 3 piers have bigger displacement of their tops; meanwhile, the No. 1 and No. 4 piers have the biggest displacement of their tops in Case $3-5.84 \mathrm{~cm}$ and $5.53 \mathrm{~cm}$, respectively. The No. 2 and No. 3 piers have the biggest displacement of their tops in Case $4-8.02 \mathrm{~cm}$ and $7.80 \mathrm{~cm}$, respectively; the displacement of the top of the piers in Case 2 is lower than in the other cases, except in Case 1 (without bearings). Figure 12(b) shows the lateral displacement of the top of the piers under the action of small earthquakes; the lateral displacement of the action of the four piers increases first and then decreases in 
different cases. The piers have a larger displacement of their tops in Case 1 than in the other cases, and smaller displacement of their tops in Case 3, which is almost $80 \%$ of the maximum displacement.

Figure 12(c) shows the longitudinal displacement of the top of the piers under the action of large earthquakes. The four piers have the lowest displacement of their tops in Case 1 ; and the biggest displacement in Case 2, i.e., $40.93 \mathrm{~cm}$, $49.01 \mathrm{~cm}, 49.28 \mathrm{~cm}$, and $40.72 \mathrm{~cm}$, respectively. The piers with aseismic bearings have similar displacement of their tops; the displacement of the top of the piers in Case 3 is approximately $60 \%$ of the displacement in Case 2 . Figure 12(d) shows the lateral displacement of the top of piers under the action of large earthquakes. The four piers in Cases 1 and 2 have almost the biggest displacement of their tops. The lateral displacement of the top of piers in Cases 3 and 5 is approximately $60 \%$ of that without bearings (Case 1).This means that aseismic bearings can effectively reduce the displacement of the piers, especially under the action of large earthquake, and LRBs have a better isolation effect than HDRBs. The results are similar to the research of Wang et al. [20], but they mainly focus on friction pendulum bearings.

6.1.6. Displacement of the Girder. Figure 13 shows the displacement of the girder in the longitudinal and lateral directions of the bridge in different cases under the action of small and large earthquakes. In different cases, the displacement of the girder is over 9 times bigger under the action of large earthquake than under the action of small earthquake. In Case 1, the girder has the lowest displacement, that is, $3.5 \mathrm{~cm}$ and $18 \mathrm{~cm}$ in the longitudinal direction and $4.5 \mathrm{~cm}$ and $26 \mathrm{~cm}$ in the lateral direction under the action of small and large earthquakes, respectively. In Case 2, the girder has the biggest displacement, namely, $8.9 \mathrm{~cm}$ and $83 \mathrm{~cm}$ in the longitudinal direction and $8.2 \mathrm{~cm}$ and $63 \mathrm{~cm}$ in the lateral direction under the action of small and large earthquakes, respectively. The girder displacement in Cases 4 and 6 is approximately $50 \%$ of that in Case 2, showing that LRBs and HDRBs have a better aseismic effect and effectively reduce the seismic load on the substructure of the bridge. The displacement of the girder in Cases 3 and 5 is approximately $80 \%$ of that in Cases 4 and 6. In all cases except Case 1, the longitudinal displacement of the girder is significantly greater than the lateral direction displacement.

6.2. Seismic Response of the Bridges with Different Pier Heights and Span Lengths. Section 6.1 studies the law of influence of different combinations of rubber bearings on the seismic performance of the continuous beam bridge with a span length and pier height of $50 \mathrm{~m}$. In order to explore the applicability of the research conclusion, this section analyzes the isolation effect of various bearing combinations on continuous girder bridges with different pier heights and span lengths.

6.2.1. Seismic Response of the Bridge with Different Pier Heights. In order to compare the impact of the change in pier height on the seismic response of the structure, the span length of the bridge remained at $50 \mathrm{~m}$ and the pier heights were $10 \mathrm{~m}, 20 \mathrm{~m}, 30 \mathrm{~m}, 40 \mathrm{~m}, 50 \mathrm{~m}$, and $60 \mathrm{~m}$, i.e., with an increment of $10 \mathrm{~m}$. As the seismic response, such as the bottom bending moment, the bottom shear force, and the top displacement of each pier similarly vary with the change of pier height, the seismic responses of the No. 2 pier under the action of large earthquakes were analyzed.

Figure 14 shows the trend of the longitudinal and lateral bending moments of the No. 2 pier in different cases as the pier height changes. Figure 14(a) shows that the longitudinal bottom bending moment of the No. 2 pier in different cases almost increases with the increase of pier height. In Case 1, when the height of the pier is $50 \mathrm{~m}$, the bending moment of the bottom of the pier reduces to a certain extent. When the height of the pier is lower, the difference of the bottom bending moment of the pier is smaller in each case, which the largest is in Case 1. With the increase in pier height, the difference between the bending moments of the bottom of the piers in various cases gradually becomes obvious. When the pier height is $60 \mathrm{~m}$, the difference in the pier's bottom bending moment decreases. With different pier heights, the bending moment of the bottom of the pier is the biggest in Case 2, as NRBs were used; the bending moments of the bottom of the pier in Cases 3 and 5 are approximately $60 \%-70 \%$ of that in Case 2, and in Cases 4 and 6, it is approximately 70\%-80\%.

As shown in Figure 14(b), the lateral bottom bending moments of the No. 2 pier in different cases present an increasing trend with the increase in pier height. When the pier height is $10-40 \mathrm{~m}$, the maximum bending moment of the bottom of the pier is in Case 1; the maximum bending moment appears in Case 2 when the pier is 50-60 $\mathrm{m}$ high, which is slightly bigger than that in Case 1. The laws of other seismic response of the bridges are similar to the law of the longitudinal bending moment of the bottom of the pier.

Figure 15 shows the trend of the longitudinal and lateral girder displacements changing with pier height in different cases. The displacement of girder increases with the increase in pier height, and the girder displacement in Case 1 is the smallest. In the cases that the bridge has bearings, the displacement of the girder in Case 2 is the maximum, while the girder displacement in Cases 3 and 5 is approximately $60 \%-70 \%$ of that in Case 2, and in Cases 4 and 6 , it is approximately $70 \%-80 \%$ of that in Case 2 .

Figure 16 shows that the longitudinal and lateral displacements of the bearings of the No. 2 pier vary with the pier height in different cases. In Case 3, the bearing displacement is the smallest, while in Case 2, the bearing 


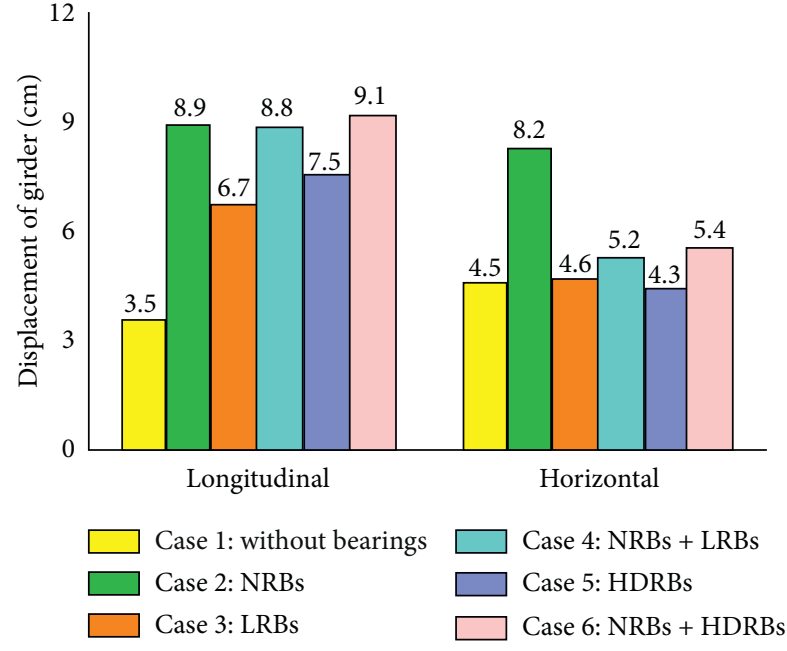

(a)

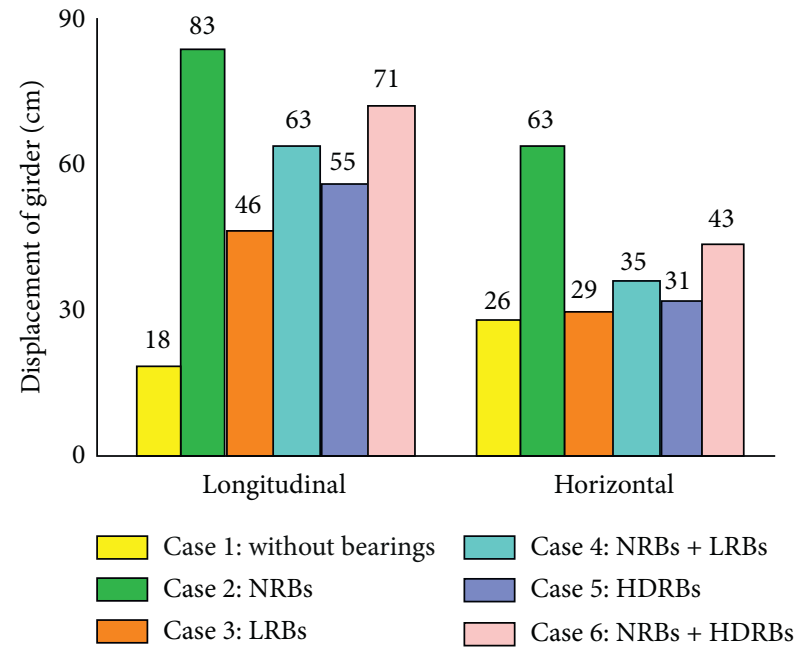

(b)

FIGURE 13: Displacement of the girder in different cases: (a) under the action of small earthquake; (b) under the action of large earthquake.

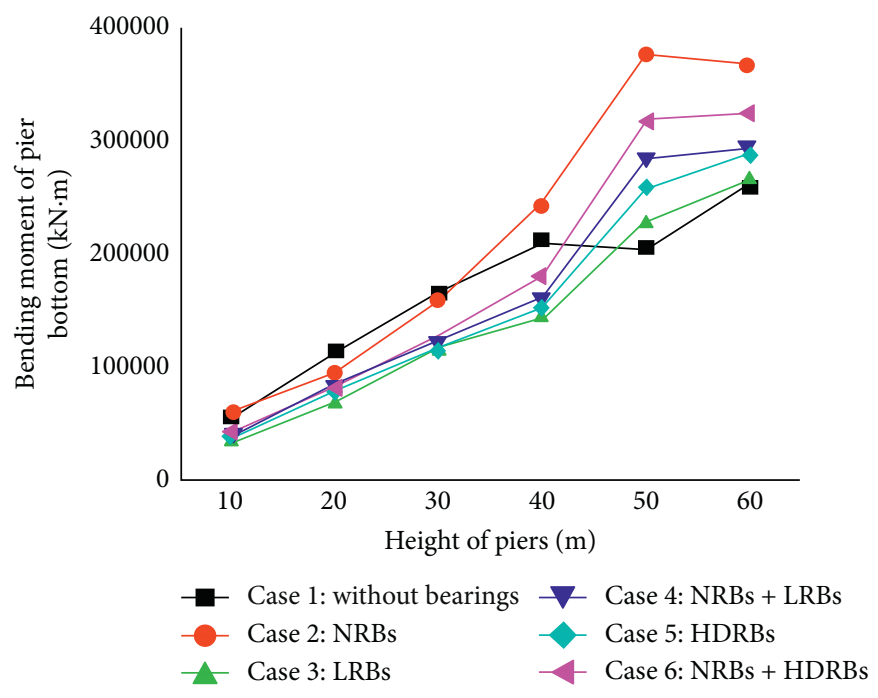

(a)

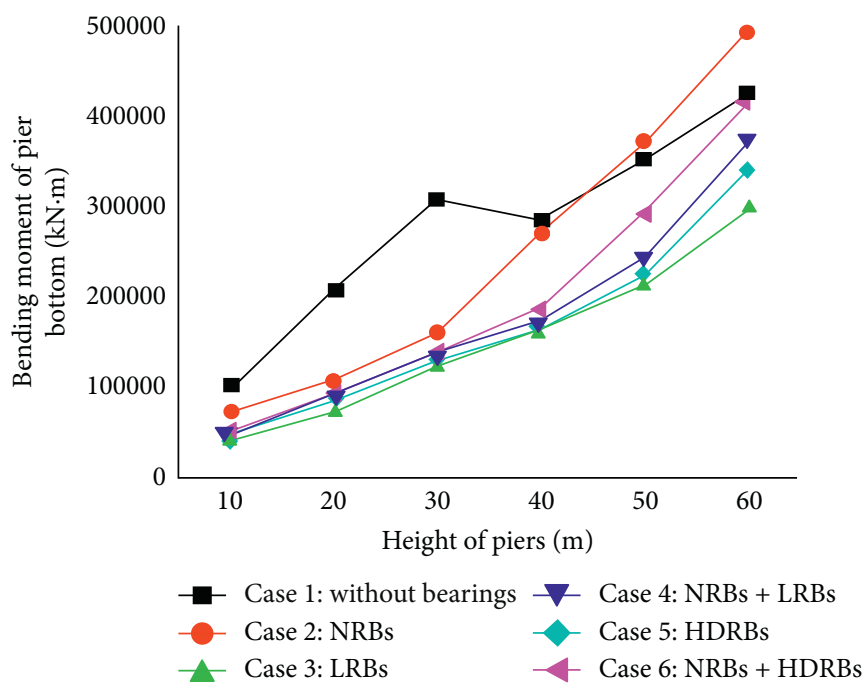

(b)

Figure 14: Bottom bending moments of the piers with the change of pier height in different cases: (a) longitudinal; (b) lateral.

displacement is the largest. In Figure 16(a), the longitudinal displacement of the bearings at the No. 2 pier basically increases first and then decreases with the increase of pier height. When the pier height is $60 \mathrm{~m}$, the displacement of the bearing decreases greatly. In Figure 16(b), the lateral bearing displacement basically increases, and only the bearing displacement in Case 2 exceeds its limiting displacement.

6.2.2. Seismic Response of the Bridges with Different Span Lengths. In this section, the pier height of the bridge remained $50 \mathrm{~m}$ and the span lengths of the bridge were $35 \mathrm{~m}$,
$40 \mathrm{~m}, 45 \mathrm{~m}, 50 \mathrm{~m}, 55 \mathrm{~m}$, and $60 \mathrm{~m}$, i.e., with an increment of $5 \mathrm{~m}$. Figure 17 shows that the longitudinal and lateral bending moments of the No. 2 pier in the different cases basically increase with the increase of span length. In the cases that the bridge with bearings, the bending moment at the bottom of the pier in Case 2 is the largest, while that in Cases 3 and 5 is approximately $60 \%-70 \%$ of that in Case 2, and in Cases 4 and 6, it is approximately $70 \%-80 \%$ of that in Case 2. In Case 1, when the bridge is without bearings, the longitudinal bending moment of the bottom of the pier is smaller than that in the other cases, while the lateral bending moment of the bottom of the pier is larger than that in other 


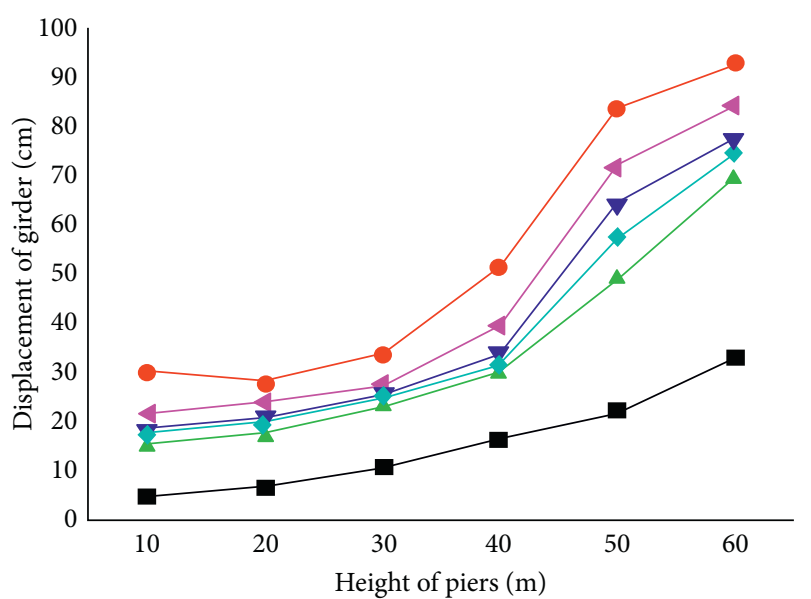

- Case 1: Without bearings
- Case 2: NRBs
- Case 3: LRBs

(a)

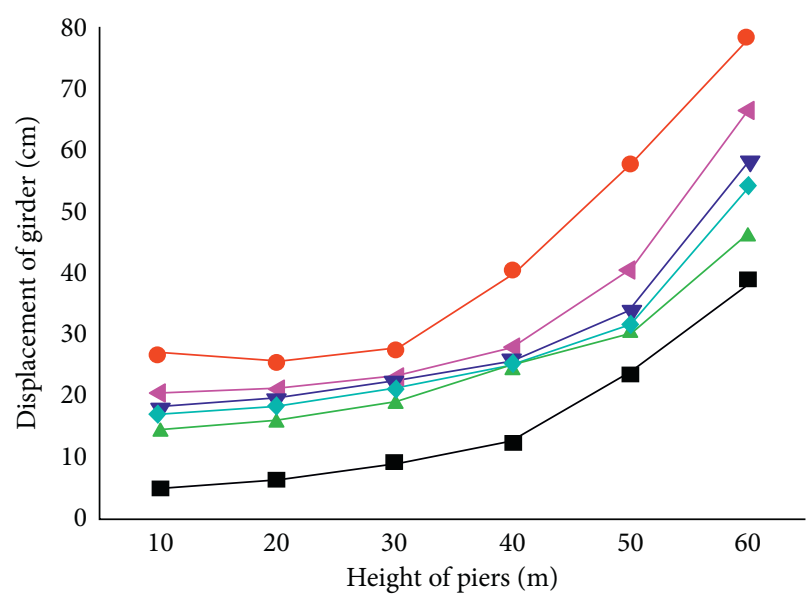

- Case 1: Without bearings
- Case 2: NRBs
- Case 3: LRBs

(b)

Figure 15: Displacement of girder with the change of pier height in different cases: (a) longitudinal; (b) lateral.

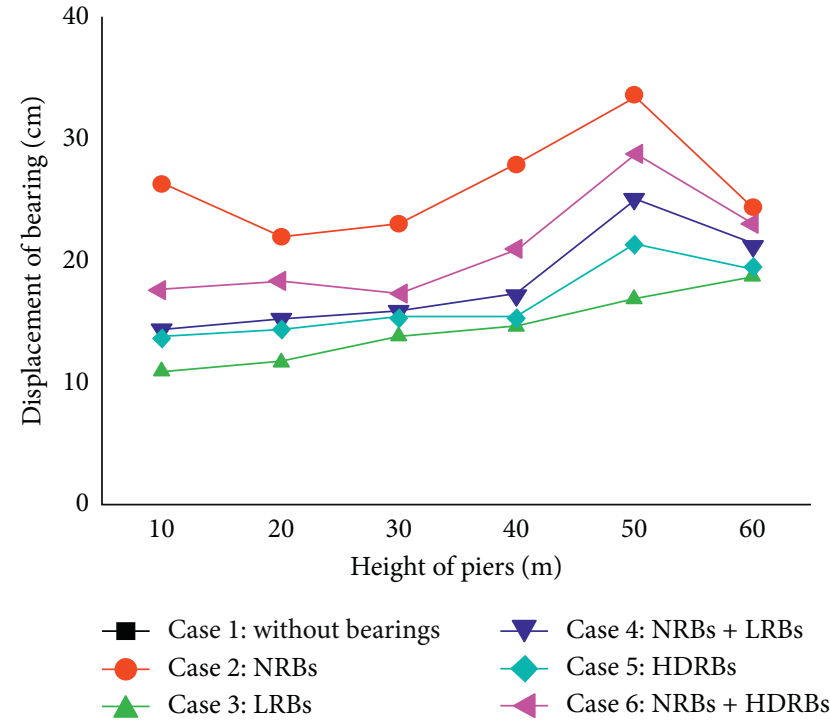

(a)

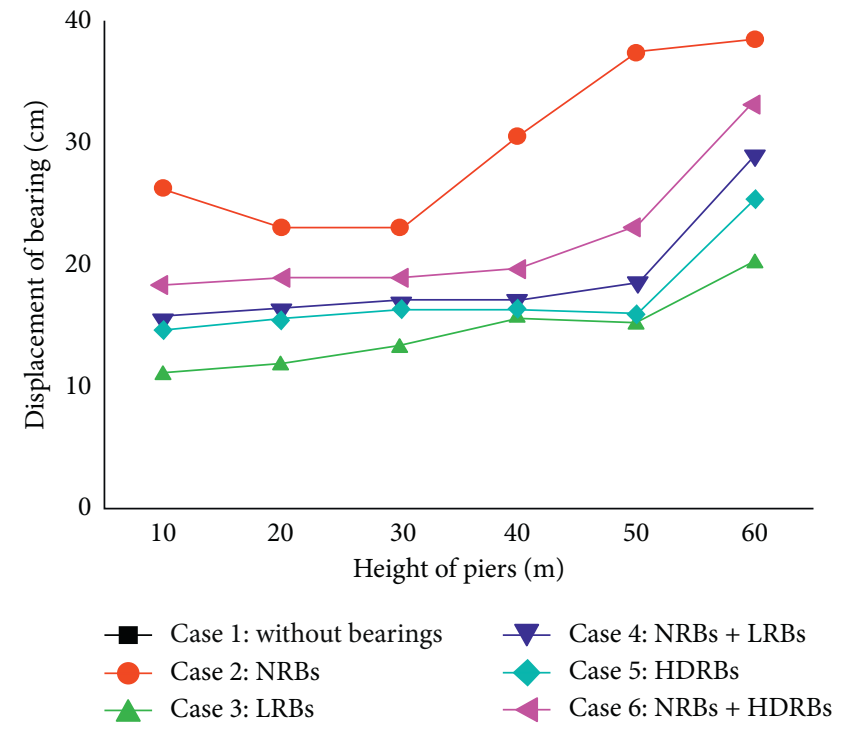

(b)

FIgURE 16: Displacement of bearings with the change of pier height in different cases: (a) longitudinal; (b) lateral.

cases. With the increase of span length, the difference in the bending moment of the bottom of the pier in various cases gradually becomes obvious. When the span length is $60 \mathrm{~m}$, the difference of the longitudinal bending moment of the bottom of the pier decreases slightly.

Figure 18 shows that the longitudinal and lateral displacements of the bearings of the No. 2 pier vary with the change of span length in different cases. In Case 2, the bearing displacement is the maximum, while in Case 3, the bearing displacement is the minimum, which is $50 \%-60 \%$ of that in Case 2. The longitudinal and lateral displacements of the bearings both increase with the increase of span length. When the span length is $60 \mathrm{~m}$, the bearing displacement decreases slightly in Case 2. However, the displacements of NRB-2 exceed the limiting displacements under the action of large earthquake in Case 2 with different span lengths. 


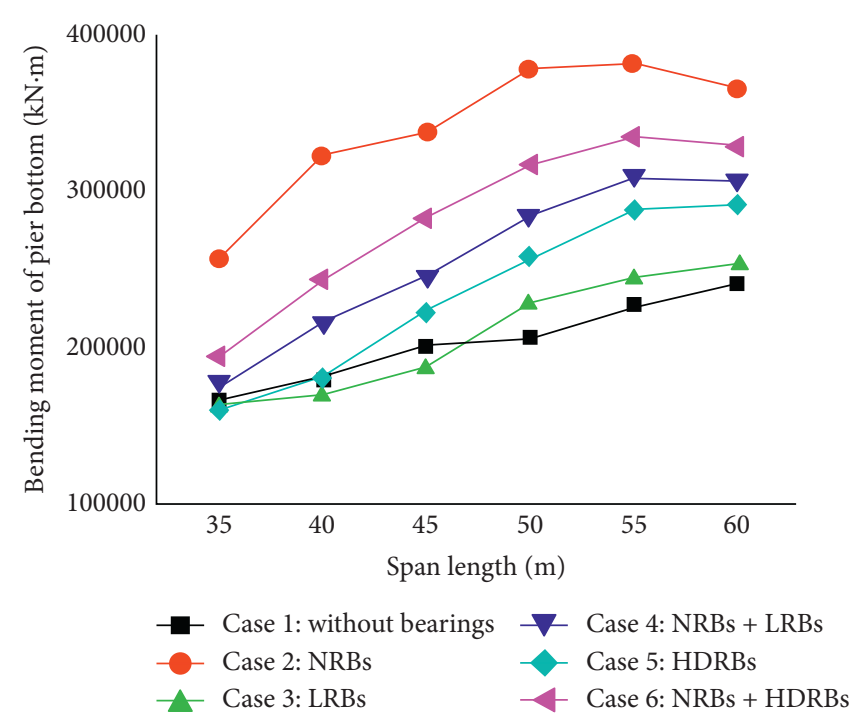

(a)

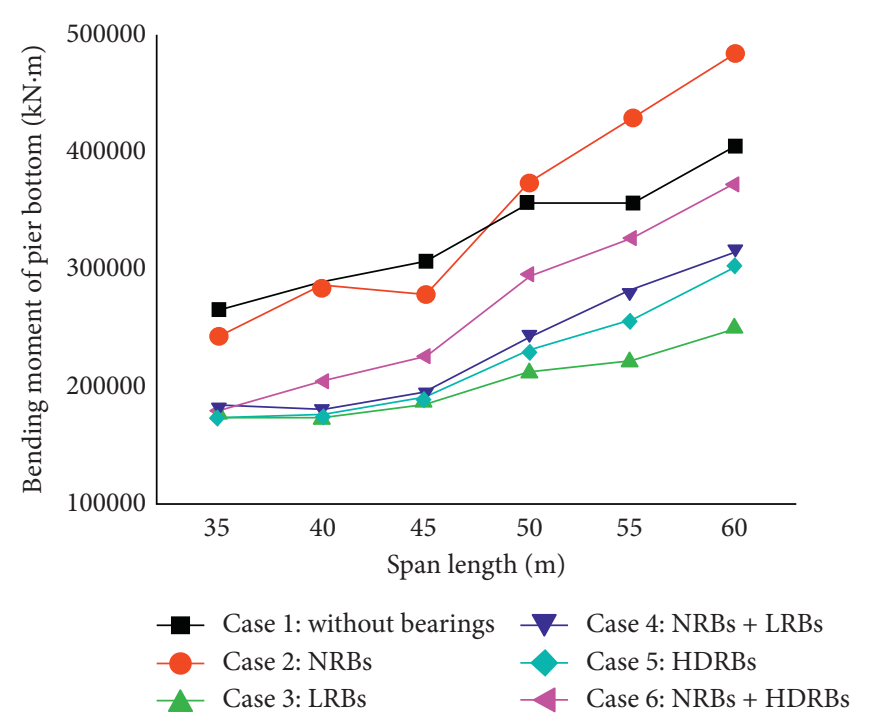

(b)

FIgURE 17: Bottom bending moment of the pier with the change of span length in different cases: (a) longitudinal; (b) lateral.

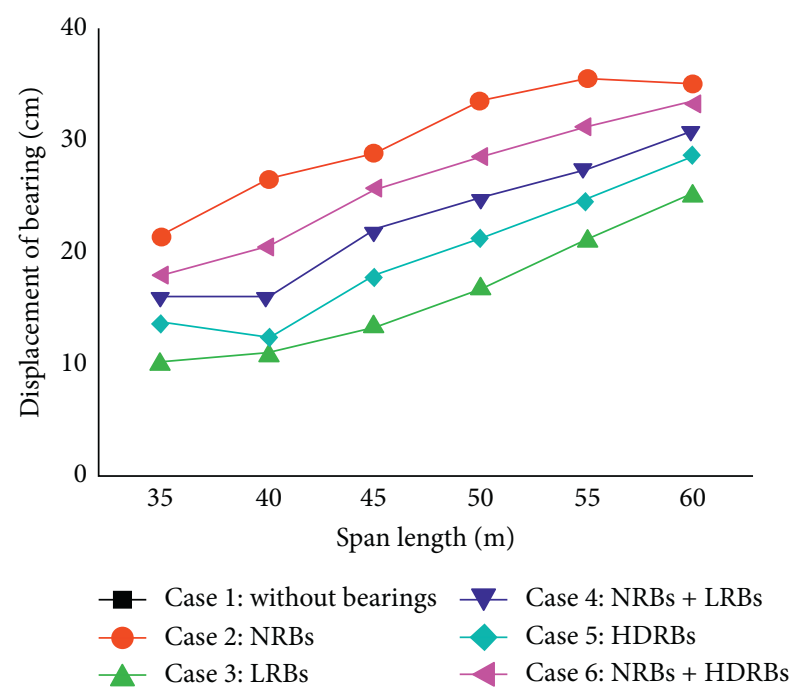

(a)

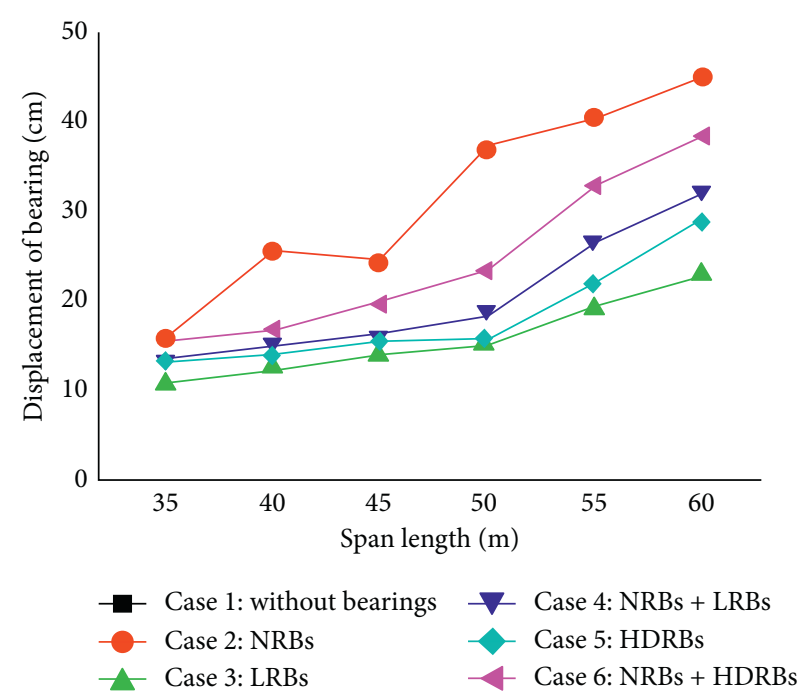

(b)

Figure 18: Displacement of bearings with the change of span length in different cases: (a) longitudinal; (b) lateral.

\section{Conclusions}

In this paper, the seismic performance of different combinations of rubber isolation bearings for the continuous beam bridges with different pier heights and span lengths under the action of small and large earthquakes was studied. The seismic effects of the different combinations of rubber bearings on the displacement, bending moment of pier, and girder displacement of the bridge under the action of earthquakes were analyzed. The main conclusions are as follows:

(1) Due to the nonlinear horizontal stiffness of LRBs and HDRBs, it was proved that the cases in which the bridge uses LRBs and HDRBs were more effective than cases with NRBs in reducing the seismic response of the continuous bridges with T-beams under the action of earthquakes. LRBs and HDRB dissipate seismic energy through yield and damping effects and show excellent isolation performance under the action of large earthquakes compared to that of other bearings.

(2) The seismic response of the bridge was lower in Cases 3 and 5 (LRBs and HDRBs) than in Cases 4 and 6 (NRBs + LRBs and NRBs + HDRBs), and much lower than in Case 2 (NRBs). The values of the 
physical quantities in Cases 3 and 5 were approximately $60 \%-70 \%$ of those in Case 2 . The seismic response of the bridge in Cases 4 and 6 are mostly between those in Case 2 and those in Cases 3 and 5 (approximately $70 \%-80 \%$ of those in Case 2). However, Cases 4 and 6 were more economical than Cases 3 and 5, as the unit price of NRBs is relatively cheaper than that of LRBs and HDRBs.

(3) No. 2 and No. 3 piers generally have bigger displacement of the tops and bigger shear force and the bending moments of the bottoms than No. 1 and No. 4 piers, especially in Cases 4 and 6 under the action of small earthquakes. More seismic loads are transmitted to the No. 2 and No. 3 piers due to the fact that No. 1 and No. 4 piers have smaller stiffness of the bearings than No. 2 and No. 3 piers. However, the bearings with lower stiffness have larger displacement than those with higher stiffness under the action of earthquakes. The larger difference in stiffness of the bearings between the side and middle piers leads to more unbalanced seismic response of each pier of the bridge structure.

(4) No matter how the pier height or the span length of the bridge changes, the law of influence of the bearing combinations on the seismic response of a bridge is similar. The seismic response of the bridge in each case was relatively close to each other when the pier height and span length were small, and the difference in the seismic response values of each case gradually increased as the pier height and span length increased. LRBs and HDRBs on all the piers are more suitable for isolation design for the continuous beam bridge with longer span and higher pier. In Cases 4 and 6, the use of cheaper NRBs underneath some girders is more reasonable for the continuous beam bridge with shorter span and lower pier.

(5) In Case 1, the piers and the girder were fixed without bearings. When the pier height was lower, the pier stiffness was larger, and the bottom bending moment of the pier was larger; as the pier height increased, the bending moment of the bottom of the pier decreased, along with the pier stiffness, which was more obvious when the pier height was $40 \mathrm{~m}$.

In this paper, the influence of the collision of adjacent bridges and different site conditions for the isolation effect of the bridge is not considered. In the future, studies will be carried out on the constructability, availability, and technical soundness of the isolation bearings for continuous beam bridges.

\section{Data Availability}

All the data used to support the findings of this study are included in the paper.

\section{Conflicts of Interest}

The authors declare that they have no conflicts of interest.

\section{Acknowledgments}

The authors are grateful for the financial support from the Shaanxi Natural Science Foundation (Grant No. 2018JQ5073) and Fundamental Research Funds for the Central Universities (Grant No. CHD300102210517).

\section{References}

[1] N. Xiang and M. Shahria Alam, "Comparative seismic fragility assessment of an existing isolated continuous bridge retrofitted with different energy dissipation devices," Journal of Bridge Engineering, vol. 24, no. 8, Article ID 0001425, 2019.

[2] Y. Li, Z. Zong, and B. Yang, "Experimental study on seismic performance of concrete continuous bridge with HDR bearings," Journal of The Institution of Engineers: Series A, vol. 101, pp. 1-22, 2020.

[3] N. Xiang, M. S. Alam, and J. Li, "Shake table studies of a highway bridge model by allowing the sliding of laminatedrubber bearings with and without restraining devices," Engineering Structures, vol. 171, pp. 583-601, 2018.

[4] Y. Zhang, Y. Shi, and D. Liu, "Seismic effectiveness of multiple seismic measures on a continuous girder bridge," Applied Sciences, vol. 10, no. 2, p. 624, 2020.

[5] A. K. M. T. A. Khan, M. A. R. Bhuiyan, and S. B. Ali, "Seismic responses of a bridge pier isolated by high damping rubber bearing: effect of rheology modeling," International Journal of Civil Engineering, vol. 17, no. 11, pp. 1767-1783, 2019.

[6] N. Xiang and J. Li, "Experimental and numerical study on seismic sliding mechanism of laminated-rubber bearings," Engineering Structures, vol. 141, pp. 159-174, 2017.

[7] A. M. Billah and B. Todorov, "Effects of subfreezing temperature on the seismic response of lead rubber bearing isolated bridge," Soil Dynamics and Earthquake Engineering, vol. 126, Article ID 105814, 2019.

[8] E. Tubaldi, S. A. Mitoulis, and H. Ahmadi, "Comparison of different models for high damping rubber bearings in seismically isolated bridges," Soil Dynamics and Earthquake Engineering, vol. 104, pp. 329-345, 2018.

[9] W. Zhang, H. Wu, H. Hwang et al., "Bearing behavior of reinforced concrete column-isolated footing substructures," Engineering Structures, vol. 200, Article ID 109744, 2019.

[10] L.-P. Guay and N. Bouaanani, "Assessment of low temperature exposure for design and evaluation of elastomeric bridge bearings and seismic isolators in Canada," Canadian Journal of Civil Engineering, vol. 43, no. 9, pp. 851-863, 2016.

[11] X. Chen and C. Li, "Seismic performance of tall pier bridges retrofitted with lead rubber bearings and rocking foundation," Engineering Structures, vol. 212, Article ID 110529, 2020.

[12] F. Paolacci, R. Giannini, and M. De Angelis, "Seismic response mitigation of chemical plant components by passive control techniques," Journal of Loss Prevention in the Process Industries, vol. 26, no. 5, pp. 924-935, 2013.

[13] W. Wang and X. Wang, "Tests, model, and applications for coned-disc-spring vertical isolation bearings," Bulletin of Earthquake Engineering, vol. 18, no. 1, pp. 357-398, 2020.

[14] N. Nakata, R. Erb, and M. Stehman, "Mixed force and displacement control for testing base-isolated bearings in realtime hybrid simulation," Journal of Earthquake Engineering, vol. 23, no. 6, pp. 1055-1071, 2019.

[15] F. Mazza and A. Vulcano, "Experimental tests and analytical modelling of a scaled isolated structure on sliding and elastomeric bearings," Advances in Materials Science and Engineering, vol. 2016, Article ID 2942194, 15 pages, 2016. 
[16] N. D. Oliveto, A. A. Markou, and A. Athanasiou, "Modeling of high damping rubber bearings under bidirectional shear loading," Soil Dynamics and Earthquake Engineering, vol. 118, pp. 179-190, 2019.

[17] K. Yamamoto, K. Fujita, and I. Takewaki, "Instantaneous earthquake input energy and sensitivity in base-isolated building," The Structural Design of Tall and Special Buildings, vol. 20, no. 6, pp. 631-648, 2011.

[18] L. R. Pradilla and G. C. Cho, "Uso de aisladores de base en puentes de concreto simplemente apoyados," Tecnura, vol. 16, no. 34, pp. 103-124, 2012.

[19] D. Losanno, H. A. Hadad, and G. Serino, "A case study on performance of isolated bridges under near-fault ground motion," Urban and Civil Engineering, vol. 11, no. 4, pp. 387-392, 2017.

[20] B. Wang, Q. Han, and J. Jia, "Seismic response analysis of isolated offshore bridge with friction sliding bearings," Earthquakes and Structures, vol. 16, no. 6, pp. 641-654, 2019.

[21] W. Zheng, H. Wang, H. Hao et al., "Performance of bridges isolated with sliding-lead rubber bearings subjected to nearfault earthquakes," International Journal of Structural Stability and Dynamics, vol. 20, no. 2, Article ID 2050023, 2020.

[22] H. Anajafi, K. Poursadr, M. Roohi, and E. Santini-Bell, "Effectiveness of seismic isolation for long-period structures subject to far-field and near-field excitations," Frontiers in Built Environment, vol. 6, Article ID 00024, 2020.

[23] L. Zhen, L. Dejian, P. Leihua, L. Yao, C. Kepei, and W. Qianqiu, "Study on the damping efficiency of continuous beam bridge with constant cross-section applied by lead rubber bearings and fluid viscous dampers," Noise \& Vibration Worldwide, vol. 51, pp. 85-92, 2020.

[24] T. Takeuchi, M. Uchida, and R. Matsui, "Response characteristics of spherical sliding bearings and superstructure subject to bidirectional ground motions," Journal of Structural and Construction Engineering (Transactions of AIJ), vol. 82, no. 739, pp. 1339-1347, 2017.

[25] Y. Bao, T. C. Becker, T. Sone, and H. Hamaguchi, "To limit forces or displacements: collapse study of steel frames isolated by sliding bearings with and without restraining rims," Soil Dynamics and Earthquake Engineering, vol. 112, pp. 203-214, 2018.

[26] F. H. Dezfuli and M. Shahria Alam, "Performance-based assessment and design of FRP-based high damping rubber bearing incorporated with shape memory alloy wires," Engineering Structures, vol. 61, no. 61, pp. 166-183, 2014.

[27] P. Tan, J.-d. Huang, C.-M. Chang, and Y. Zhang, "Failure modes of a seismically isolated continuous girder bridge," Engineering Failure Analysis, vol. 80, pp. 57-78, 2017.

[28] H. S. Gu and Y. Itoh, "Ageing behaviour of natural rubber and high damping rubber materials used in bridge rubber bearings," Advances in Structural Engineering, vol. 13, no. 6, pp. 1105-1113, 2010.

[29] B. D. Liu, S. Z. Yang, W. L. Li, and M. Q. Zhang, "Damping dissipation properties of rubberized concrete and its application in anti-collision of bridge piers," Construction and Building Materials, vol. 236, Article ID 117286, 2020.

[30] J.-C. Li, H.-S. Zhang, X.-Y. Zhao et al., "Development of high damping natural rubber/butyl rubber composites compatibilized by isobutylene-isoprene block copolymer for isolation bearing," Express Polymer Letters, vol. 13, no. 8, pp. 686-696, 2019.

[31] A. A. Markou and G. D. Manolis, "Numerical solutions for nonlinear high damping rubber bearing isolators: newmark's method with netwon-raphson iteration revisited," Journal of
Theoretical and Applied Mechanics, vol. 48, no. 1, pp. 46-58, 2018.

[32] W. Wei, P. Tan, Y. Yuan, and H. Zhu, "Experimental and analytical investigation of the influence of compressive load on rate-dependent high-damping rubber bearings," Construction and Building Materials, vol. 200, pp. 26-35, 2019.

[33] Q. Rong, "Optimum parameters of a five-story building supported by lead-rubber bearings under near-fault ground motions," Journal of Low Frequency Noise, Vibration and Active Control, vol. 39, no. 1, pp. 98-113, 2020.

[34] K. Bhowmik and P. Saha, "Seismic response control of benchmark highway bridge using passive hybrid control systems," International Journal of Materials and Structural Integrity, vol. 11, no. 4, pp. 155-174, 2017.

[35] G. Augusti, "Dynamics of structures: theory and applications to earthquake engineering," Meccanica, vol. 31, no. 6, pp. 719-720, 1996.

[36] J. Guo, J. Zhong, X. Dang, and W. Yuan, "Influence of multidirectional cable restrainer on seismic fragility of a curved bridge," Journal of Bridge Engineering, vol. 24, no. 3, Article ID 04019001, 2019.

[37] H. Gou, W. Zhou, Y. Bao, X. Li, and Q. Pu, "Experimental study on dynamic effects of a long-span railway continuous beam bridge," Applied Sciences, vol. 8, no. 5, p. 669, 2018.

[38] E. Choi, R. Desroches, and B. Nielson, "Seismic fragility of typical bridges in moderate seismic zones," Engineering Structures, vol. 26, no. 2, pp. 187-199, 2004.

[39] J. Zhang and Y. Huo, "Evaluating effectiveness and optimum design of isolation devices for highway bridges using the fragility function method," Engineering Structures, vol. 31, no. 8, pp. 1648-1660, 2009.

[40] M. S. Alam, M. A. Youssef, and M. Nehdi, "Analytical prediction of the seismic behaviour of superelastic shape memory alloy reinforced concrete elements," Engineering Structures, vol. 30, no. 12, pp. 3399-3411, 2008.

[41] F. D. Julian, T. Hayashikawa, and T. Obata, "Seismic performance of isolated curved steel viaducts equipped with deck unseating prevention cable restrainers," Journal of Constructional Steel Research, vol. 63, no. 2, pp. 237-253, 2007.

[42] A. H. Billah and M. S. Alam, "Seismic performance of concrete columns reinforced with hybrid shape memory alloy and fiber reinforced polymer bars," Construction and Building Materials, vol. 28, no. 1, pp. 730-742, 2012.

[43] N. Xiang and J. Li, "Utilizing yielding steel dampers to mitigate transverse seismic irregularity of a multi-span continuous bridge with unequal height piers," Engineering Structures, vol. 205, Article ID 110056, 2020.

[44] C. P. Providakis, "Effect of LRB isolators and supplemental viscous dampers on seismic isolated buildings under nearfault excitations," Engineering Structures, vol. 30, no. 5, pp. 1187-1198, 2008.

[45] S. A. Mitoulis, "Uplift of elastomeric bearings in isolated bridges subjected to longitudinal seismic excitations," Structure and Infrastructure Engineering, vol. 11, no. 12, pp. 1600-1615, 2015.

[46] D. Cardone, M. Dolce, and G. Palermo, "Direct displacementbased design of seismically isolated bridges," Bulletin of Earthquake Engineering, vol. 7, no. 2, pp. 391-410, 2009.

[47] Z. Li, Ri Gao, and W. Jia, "Design and experimental study on shock-absorbing steel bar with limit function for bridges," Shock and Vibration, vol. 2019, Article ID 3096291, 10 pages, 2019.

[48] L. Jiang, X. Kang, C. Li, and G. Shao, "Earthquake response of continuous girder bridge for high-speed railway: a shaking 
table test study," Engineering Structures, vol. 180, pp. 249-263, 2019.

[49] K. Kalfas, S. A. Mitoulis, and D. Konstantinidis, "Influence of the steel reinforcement on the vulnerability of elastomeric bearings," ASCE Journal of Structural Engineering, vol. 146, no. 10, Article ID 04020195, 2020.

[50] Y. Li, J. J. Wang, and J. B. Liu, "Seismic performance of a multi-span rc highway bridge with high damping rubber bearings," Key Engineering Materials, vol. 540, pp. 69-78, 2013.

[51] K. N. Kalfas, S. A. Mitoulis, and K. Katakalos, "Numerical study on the response of steel-laminated elastomeric bearings subjected to variable axial loads and development of local tensile stresses," Engineering Structures, vol. 134, pp. 346-357, 2017.

[52] X. Wang, B. Zhu, and S. Cui, "Research on collapse process of cable-stayed bridges under strong seismic excitations," Shock and Vibration, vol. 2017, Article ID 7185281, 18 pages, 2017.

[53] A. R. Bhuiyan and M. Shahria Alam, "Seismic performance assessment of highway bridges equipped with superelastic shape memory alloy-based laminated rubber isolation bearing," Engineering Structures, vol. 49, pp. 396-407, 2013.

[54] C. Lu, M. Gui, and S. Lai, "A numerical study on soil-grouppile-bridge-pier interaction under the effect of earthquake loading," Journal of Earthquake and Tsunami, vol. 8, no. 1, Article ID 1350037, 2014.

[55] M. A. R. Bhuiyan and M. Shahria Alam, "Seismic vulnerability assessment of a multi-span continuous highway bridge fitted with shape memory alloy bars and laminated rubber bearings," Earthquake Spectra, vol. 28, no. 4, pp. 1379-1404, 2012.

[56] L. Wang, J. Su, Z. Gu et al., "Numerical study on flow field and pollutant dispersion in an ideal street canyon within a real tree model at different wind velocities," Computers and Mathematics With Applications, 2020.

[57] J. Li, N. Xiang, H. Tang, and Z. Guan, "Shake-table tests and numerical simulation of an innovative isolation system for highway bridges," Soil Dynamics and Earthquake Engineering, vol. 86, pp. 55-70, 2016.

[58] J. Yi, H. Yang, and J. Li, "Experimental and numerical study on isolated simply-supported bridges subjected to a fault rupture," Soil Dynamics and Earthquake Engineering, vol. 127, Article ID 105819, 2019.

[59] Y.-I. Kim and G.-J. Park, "Nonlinear dynamic response structural optimization using equivalent static loads," Computer Methods in Applied Mechanics and Engineering, vol. 199, no. 9-12, pp. 660-676, 2010. 